\title{
POBLACIÓN Y DESARROLLO RURAL EN CENTROAMÉRICA
}

\author{
Andrés Opazo Bernales \\ Universidad Rodrigo Facio
}

LA INTERACCIÓN entre la dinámica de población y la estructura o el desarrollo rural puede ser abordada desde dos perspectivas diferentes aunque complementarias. Se puede considerar la población, en primer lugar, desde el punto de vista de su volumen, composición y desarrollo o niveles de crecimiento. En segundo lugar, se la puede observar en cuanto a su distribución en el espacio físico y a su movilización dentro de tal espacio. Ambas perspectivas son susceptibles de un análisis orientado a determinar la forma en que la población se enraiza en una determinada estructura productiva, esto es, una forma concreta de división y organización del trabajo social sin el cual la población misma no puede reproducir sus condiciones de existencia. Si esta estructura económica es en esencia rural en la región que nos ocupa, resulta oportuno y pertinente interrogarse por la relación entre la dinámica propia de la población y la estructura y el desarrollo rural.

En estas páginas no encontraremos un pensamiento elaborado al respecto, sino una cierta sistematización de inquietudes que pueden permitir la definición de algunas líneas de investigación útiles para el conocimento de nuestra región. Parece conveniente intentar la aproximación a un modelo explicativo global del funcionamiento del agro centroamericano, que posibilite la comprensión de los fenómenos de población en relación al sistema que origina las condiciones de su supervivencia y reproducción. Luego, y dentro de los marcos de esta sistematización tentativa, se elaborarán algunas ideas respecto de la forma como debería abordarse el problema de la producción de una "marginalidad" campesina. Por último se sacarán algunas conclusiones para el estudio de la población, tanto sobre su dinámica interna, como en términos de su desplazamiento en el espacio.

El énfasis que en este documento adquieren los desplazamientos de la población en el espacio, fuera de manifestar las preocupaciones actuales del autor, se puede fundamentar por la importancia que de manera hipotética se les puede asignar como respuestas de la población a las condiciones, favorables o desfavorables, que le ofrece el medio, natural y social, para perpetuar y mejorar su existencia. Creemos que las propias 
variables que dan cuenta de la estructura y dinảmica interna de la población pueden ser fructuosamente analizadas si se consideran, tanto la distribución espacial de la población como sus desplazamientos.

\section{El capitalismo agrario CENTRoAmericano}

Ya parece ser una adquisición fundamental en algunos medios científicos, aunque sin duda preliminar, la afirmación de que el capitalismo centroamericano no repite, sin más, la historia de su antecesor europeo. Se sabe que la llegada del capitalismo a la región, mercantil en su comienzo, debió asentarse sobre una base, productiva y social, obviamente no capitalista. Al respecto, el gran problema teórico-empírico que habría que resolver es la forma como se articula la estructura económica y social que logró una consolidación efectiva y duradera en el período colonial, con la estructura que el capitalismo necesita como la más adecuada para su pleno desarrollo. La síntesis lograda en Centroamérica reviste una especificidad, posiblemente aun respecto de las restantes sociedades latinoamericanas, lo que justifica una somera revisión de los planteamientos más en boga.

El capitalismo se consolida en Centroamérica como un sistema organizador de la producción de bienes agropecuarios destinados al mercado externo. A fin de implantar su propia racionalidad, éste debe promover a fondo una conveniente "reforma agraria" que posibilite, en lo mínimo, la división del trabajo sin la cual no puede persistir. No obstante las considerables transformaciones sociales acarreadas, la producción capitalista y su nueva organización social no pueden remover siglos de historia, y debe acomodarse, en más de un aspecto importante -en particular en lo tocante a las formas de tenencia de la tierra-, a una estructura de propiedad y a una división del trabajo no propiamente capitalista.

Decimos de manera consciente "no capitalista" al preferir no emplear por ahora el término, posiblemente más cómodo, de "precapitalista". En efecto, cuando hablamos de formas precapitalistas para oponerlas a las formas propiamente capitalistas de organización de la producción, se presupone, gracias al prefijo "pre", una secuencia temporal, en la que una forma es seguida por la otra, dado que la distinción entre ambas es en esencia cronológica. Este contenido semántico conduce con facilidad hacia otras proposiciones que podrían llegar a ser francamente discutibles. Nos referimios al supuesto, no siempre reflexionado de manera crítica, de que la forma de tenencia de la tierra y la organización de la producción a ella anexa, que podríamos llamar provisoriamente señorial, es siempre anterior al capitalismo, que es disuelta por éste, dentro de una secuencia histórica previamente aceptada como una premisa indiscutida por evidente. ${ }^{1}$ A la división del trabajo social de corte señorial le sigue "natu-

1 Al respecto, existe una "verdad" repetida en muchos medios académicos que afirma que los rasgos feudales o señoriales que permanecen en el agro latinoame- 
ralmente" la división del trabajo capitalista, y si se observa la coexistencia temporal de rasgos de dos modos de producción diferentes, se dice, sin más, que lo que ocurre es la presencia de un proceso de transición. En apariencia, todo queda solucionado. Estaríamos en el preciso instante en que desaparecen los rasgos señoriales al paso que aparecen en escena los capitalistas. No pretendemos negar la duración en la historia de los procesos de transición. Pero también es cierto que en la actualidad las cosas no cambian al ritmo en que se dieron las transformaciones de fines del medioevo. Creemos que la explicación de la coexistencia mencionada debe ir más allá, sobre todo cuando observamos la paradoja de una gran "estabilidad" temporal de esta "transición", que hunde sus raíces en las reformas liberales de mediados del siglo pasado y que se prolonga en sociedades en donde se avanza en un proceso de industrialización, como es el caso de El Salvador. La explicación basada puramente en una distinción de fases históricas muy generales es claramente insuficiente.

Por el contrario, es probable que se requiera determinar con la mayor precisión posible la especificidad de la formación social centroamericana, en donde parece verificarse una particular forma de adaptación del capitalismo que integra en su modo de operar elementos que en otros contextos históricos le son ajenos, y que no figuran en la consideración teórica del capitalismo en su estado puro.

Esta combinación histórica de carácter "dualista" ha adquirido una fisonomía propia, ha alcanzado una estabilidad que no se podría cuestionar, que hace que en plena "era del jet", en la que los ejecutivos de San José se reúnen en hora y media con los de Guatemala para decidir en conjunto una operación común, persistan formas de producción "arcaicas". Lo más probable es que no haya que considerarlas como arcaicas, sino como la respuesta del capitalismo moderno centroamericano a las circunstancias particulares de su desarrollo, esto es, como un reflejo de la lógica capitalista, de su racionalidad más esencial definida genéricamente por la ganancia privada.

No se podría pretender que con esto se quiere minimizar la perspectiva histórica para analizar los procesos sociales. Sin ella no es posible la comprensión de los fenómenos. Es irremplazable en la explicación causal, de allí que proposiciones como las siguientes arrojen inmensa luz

ricano, van desapareciendo por la generalización de las relaciones capitalistas. Esto debe ser cierto a largo plazo, pero habría que investigarlo en periodizaciones concretas. Afirmaciones generales como ésta muchas veces no son más que repeticiones de una teoría macrosocial, perfectamente válida, acerca de las grandes etapas de la historia. Sin embargo, la aplicación acrítica de esta teoría a la realidad social concreta opera como una cortina de humo sobre ésta. Por ejemplo, relaciones llamadas precapitalistas, como el colonato, lejos de disminuir en un país tan poblado y el más industrializado de Centroamérica como El Salvador, muestran una tendencia al aumento. Aquí, la aplicación fácil de la teoría se encontraría con contradicciones quizás insuperables al nivel de generalidad en que se aplica la teoría. 
sobre el problema: "La 'dualidad' estructural le llega a Centroamérica por herencia colonial que el último cuarto de siglo transcurrido no logra debilitar; la demanda externa impuso una infraestructura económica que favorecía el monocultivo; la estructura colonial que la independencia no pudo remozar puso el resto; y, por añadidura, el tipo de cultivos como el algodón y el café facilitaron la monopolización de la tierra primero y de inmediato la concentración del ingreso, la oligarquización del prestigio y del poder y por último, la rigidez de toda la estructura social. Se habla de 'dualidad' sólo para recordar el primero y todavía el más importante de los efectos causados -0 producidos - por la modernización colonial capitalista en la periferia tradicional". ${ }^{2}$ Es esa "modernización colonial capitalista" la que es objeto de nuestras preocupaciones. Lo interesante es que justamente en la mencionada periferia, que conserva rasgos tradicionales, se ha implantado un capitalismo que adquiere algunas particularidades específicas, como es la de combinar esos rasgos con las formas más desarrolladas de industrialización.

Al partir de la verificación histórica, el esfuerzo teórico se debería orientar, en la actualidad, hacia la comprensión de la lógica interna de este capitalismo específico, de su racionalidad más esencial, que dé cuenta de sus anomalías, como es el caso de que incorpora elementos propios de un capitalismo maduro, como el de la concentración monopólica, sin abandonar elementos ajenos al capitalismo, que en otras latitudes son disueltos por éste. En esta tarea no nos consideramos innovadores, sino que pretendemos sistematizar desde nuestra perspectiva, desde el ángulo en que se describen las líneas explicativas de los movimientos de población, nociones elaboradas por otros investigadores, en especial de la región.

\section{La industria}

Antes de centrarnos en la caracterización del capitalismo agrario, que para nosotros es lo esencial, conviene señalar algunos aspectos considerados relevantes de la industrialización en la región. Ya ha sido observado de manera suficiente que la industria en la región no ha surgido, como en otras partes, victoriosa de una pugna con formas de producción artesanales o señoriales. Tal como lo observa un autor centroamericano, "es en el sector agrícola donde se ha generado la acumulación de capital requerida, en franco apoyo al capital monopolista, en el sector industrial que cobra importancia en el decenio del sesenta con el proceso de integración económica, ahora en crisis. Ello explica la convergencia de intereses para mantener una estructura agraria deformada y deformante, paripassu con el crecimiento de la producción industrial. Más aún, el tipo

2 Edelberto Torres Rivas, Interpretación del desarrollo social centroamericano, San José, Costa Rica, EDUCA, 1973, p. 189. 
de desarrollo no requiere de la realización de reformas". 3 La industria no ha requerido de la modificación de una economía básicamente agraria. No ha necesitado de la liberación de una fuerza de trabajo de sus lazos serviles, desde el momento en que, como prolongación de economías no contradictorios con el sector terrateniente, dominante por tradición, no muy necesitada de mano de obra. Además, dado que responde a intereses no contradictorios con el sector terrateniente, por dominante tradición, no se ha visto urgida a recurrir a una elevación de la tasa de salarios en el agro, que en condiciones diferentes podría haber necesitado a fin de crear su propio mercado. La burguesía, como lo dice el estudio recién citado, ha podido echar mano de otro expediente sin coartar sus intereses agrarios. En efecto, ha optado por aliarse a las grandes corporaciones multinacionales, las que, a la par del aporte financiero y tecnológico, le ofrece la posibilidad de conformar un mercado aditivo, que no se ve tan apremiado por el imperativo de la expansión. Dadas las condiciones de concentración del ingreso, basta con la profundidad que ofrece una demanda, reducida en términos de sectores sociales, pero lo suficiente elástica como para volver rentable la producción industrial. No desconocemos que las primeras industrias, las de textiles, alimentos, bebidas, vestuario y más tarde las de plásticos, han demostrado en el inicio de sus operaciones un desarrollo expansivo de consideración. Han debido crear su propio mercado al sustituir los productos artesanales por los industriales. Tampoco se puede negar un cierto dinamismo expansivo con el crecimiento de los sectores medios. Perö consideramos que estos elementos expansivos están lejos de constituir un rasgo sobresaliente del sistema.

Este tipo de industria puede llegar a alcanzar una tasa de crecimiento muy elevada, sin desbordar sus propios límites sectoriales, esto es, sin generalizar el desarrollo; puede manifestar un gran dinamismo aunque carente de todo afán expansionista, al estar en realidad la cuestión decisiva determinada por el destino que se le dé a los excedentes. Por esto no resulta contradictorio afirmar que el desarrollo industrial centroamericano no logra alterar la matriz agrario-exportadora que aún caracteriza a las economías de la región. El excedente industrial puede destinarse tanto a una profundización tecnológica dentro del sector, que sin expandirlo crea condiciones de acumulación de capital muchísimo más favorables, o puede orientarse hacia una tecnificación agrícola, con efectos similares para la acumulación, o por último puede destinarse al consumo suntuario, a servir de reservas en el extranjero. Pero no tiene por qué verse compelido a expandir el mercado de trabajo o a mejorar el nivel de vida de fas masas trabajadoras.

El dinamismo del sector industrial se puede comprobar por su participación creciente en el producto interno bruto (PIB), a costa del sector

3 Rafael Menjívar, "Estructura agraria centroamericana y sus implicaciones", Programa Centroamericano de Ciencias Sociales, Confederación Universitaria Centroamericana, Mimeo., p. 3. 
agrícola. Aunque el ascenso no es exagerado, en un espacio de diez años, la época de mayor impulso (1956 a 1965), aumenta de 11.9 a $15 \%$ mientras se reduce la del sector agrícola de $37 \%$ a $33 \% .{ }^{4}$ Esta tendencia de ascenso y descenso correlativo se ha acentuado de manera notable en el último decenio, aunque al descenso de la agricultura corresponda en mayor grado un ascenso en los servicios. Pese al alza del sector industrial, su agravitación en la economía centroamericana es todavía reducida. E1 "sueldo" de Centroamérica sigue siendo el café, el banano, el algodón, el azúcar, la carne y la madera. Es indiscutible que la economía sigue siendo agraria; en 1960, sólo seis productos agropecuarios registran $82 \%$ del total de las exportaciones de la región, pero en 1972 baja a $68 \%$ ya que por efectos del Mercado Común Centroamericano, aumentan las exportaciones de los países centroamericanos entre ellos. ${ }^{5}$

Pero desde el punto de vista de nuestro interés, los fenómenos de la población, nuestra atención se centra sobre todo en el volumen y evolución del empleo industrial comparado con los otros sectores. Al tomar en cuenta que el esfuerzo de industrialización se inicia en los años cincuentas, de manera aproximada se puede constatar que, en la práctica, el nivel de empleo del sector secundario no evoluciona hasta la fecha. En un excelente estudio dirigido por CEPAL, OEA, SIECA, FAO y otros organismos internacionales, se dice que el sector industrial "sólo ha permitido una absorción de fuerza de trabajo de $2.7 \%$ al año, inferior a la tasa de crecimiento de la población urbana $(3.9 \%) " .6$ Por otra parte, la participación del empleo industrial en el total de la población económicamente activa (PEA) no ha variado en forma significativa desde 1950 hasta la fecha. Para Centroamérica, entre 1950 y 1963 ha ascendido sólo a una tasa media de $10.2 \%$ a $11 \%$ sin ningún indicio de que desde 1963 hasta la fecha haya variado.

Esto no impide que las remuneraciones en el sector sean en realidad más altas que en el resto de la economía, lo que unido a la intensa acumulación mencionada, se puede traducir en una participación ascendente de la industria en el PIB, lo que se aprecia en las cifras precedentes. En el período comprendido entre 1950 y 1966 la actividad secundaria ha crecido a una tasa de $7.2 \%$ anual, lo cual no resulta de ninguna manera despreciable. ${ }^{7}$ Esto no hace más que confirmar la tesis de un probable dinamismo del sector que no se traduce en la deseada expansión, en términos de diversificación interna y de oportunidades de empleo. En definitiva, la industrialización no logra alterar la estructura agraria básica

4 Jorge Arias, "La industrialización y el crecimiento de la población", en Población y recursos en Centroamérica, Universidad de Costa Rica, Ciudad Universitaria "Rodrigo Facio", 1969, p. 198.

5 SIECA, Serie de Estadísticas Seleccionadas de Centroamérica y Panamá, Núm. 14.

C CEPAL, FAO, OIT, IICA, SIECA, OCT, OEA, Tenencia de la tierra y desarrollo rural en Centroamérica, San José, Costa Rica, EDUCA, 1973, p. 23.

7 Ibid. 
de la economía centroamericana. No origina, como se aprecia en el desarrollo del capitalismo europeo, un fenómeno de liberación de fuerza de trabajo campesina, no se constituye en un factor de concentración espacial de la población, ya que no la necesita en el grado en que el capitalismo europeo naciente la necesitó. En síntesis, la actividad industrial no se desenvuelve a costa de la actividad rural, con lo cual se podría adelantar que no se debiera presentar a la manera clásica la contradicción campo-ciudad. Tampoco habría que ver a la burguesía industrial como una clase emergente que asciende en lucha franca con la clase terrateniente. Todo parece indicar que la industrialización se constituye en la región dentro de un proceso armónico y proporcionado a las exigencias y vicisitudes del desarrollo del capitalismo agrario. Ya se podrá apreciar la importancia que estos factores deben tener para el análisis de los asentamientos y desplazamientos de la población. Desde el punto de vista de las migraciones internas se advierte la dificultad para considerar la industrialización como un factor de atracción de población, lo cual autoriza a afirmar que si se percibe una corriente migratoria desde áreas rurales hacia áreas urbanas, la explicación apropiada habrá que encontrarla en otros factores, pero en ningún caso en la industria.

\section{El capitalismo agrario}

Para algunos autores, el capitalismo entra a América Latina con la propia colonización, en la medida en que ésta destruye las formas de producción anterior, implantando nuevas que se orientan de manera fundamental hacia el mercado externo, las que a la postre se convierten en un poderoso factor de acumulación de capital que hace posible la revolución industrial. Pensamos que en el largo período de la colonia no se puede constatar en términos de la organización social del trabajo, o de manera más precisa de las relaciones de producción, que es lo que nos interesa aquí, el predominio en Iberoamérica del modo de producción capitalista, sino lo que existe es un específico modo de producción colonial, con características que lo apartan tanto del modo de producción feudal como del modo de producción capitalista europeo. ${ }^{8}$ Es probable que el capitalismo se consolide en Centroamérica con las reformas liberales de mediados del siglo pasado, que impulsan la expropiación de tierras, al liberar un cierto contingente de campesinos para convertirlos en fuerza de trabajo relativamente más desarraigada de la tierra y obligada a emplearse en las haciendas que se acondicionan para la producción de café, adoptando patrones más adecuados a los cánones del capitalismo agrario. Decimos relativamente desarraigada. Veremos que lo que se va a desarro-

${ }^{8} \mathrm{Al}$ respecto se pueden consultar los trabajos del profesor Ciro F. S. Cardoso, aparecidos en los números 1 y 3 de la revista Estudios Sociales Centroamericanos, San José, Costa Rica. 
llar es otra forma de ligazón de la fuerza de trabajo a la tierra, más acorde con la producción capitalista para el mercado externo, pues en ningún caso se observa en forma generalizada un puro y simple asalariado agrícola. El capitalismo debe, de cierta manera, adaptarse a la sociedad colonial.

Como bien señala Torres Rivas, cuando el desarrollo no corresponde a causas endógenas, sino que es importado desde fuera, el traslado técnico de las fuerzas productivas, que normalmente deberían considerarse como el motor del desarrollo capitalista, "se inserta adaptándose socialmente a las condiciones propias de la etapa de desarrollo de la sociedad huésped". ${ }^{9}$ Es aquí donde aparece con validez plena la cuestión anterior acerca del carácter transitorio o estable del capitalismo agrario centroamericano. En realidad no resulta muy útil para el análisis la asimilación de la particularidad de esta forma de capitalismo a la impureza de una etapa de transición, aunque sin duda a largo plazo se trate de un momento de transición. Esta "transición" puede definir una fase con suficiente consistencia, la época de una forma específica de capitalismo, un capitalismo "híbrido", en donde se advierte la presencia de poderosos cromosomas señoriales, de los cuales no se podría afirmar de manera muy fundada que se encuentran en un proceso de extinción. Esta virtual extinción, que se podría demostrar empíricamente, no parece ser efectiva por lo menos durante los últimos veinte años.

Al retomar algo de lo que ha sido elaborado por diversos autores, podríamos asignar algunos rasgos específicos a este capitalismo, que penetra hace más de un siglo y que persiste vigoroso en la actualidad, rasgos que revisten importancia para un estudio de los procesos poblacionales:

a) En primer lugar, se trata de un capitalismo que se da de manera principal en el campo y no en la ciudad. Este elemento, tan obvio como esencial, tiene la virtud de ponernos en guardia ante la asociación, postulada en otras regiones, entre capitalismo y urbanización, lo cual será de trascendencia innegable para los movimientos de población. El capitalismo data al menos de un siglo como modo de producción dominante en la región, en tanto que el fenómeno de la urbanización es reciente. Además, según los censos del decenio de los sesentas, la población rural alcanza en Centroamérica proporciones muy elevadas, las mayores de América Latina, lo cual habría que explicar por la peculiaridad del desarrollo capitalista en la región;

b) Se trata de un capitalismo que, como se ha señalado, no surge de un conflicto con las clases dominantes del modo de producción anterior. Éste es otro factor a considerar, que debería llevar a relativizar la relación entre la acumulación capitalista y la concentración espacial de la población como una pareja de igual covariación. El capitalismo, al penetrar en el agro centroamericano innova profundamente los procesos y

9 Edelberto Torres-Rivas, op. cit., p. 189. 
estructuras de asentamiento de la población agrícola. Pero estos procesos no están determinados por la lucha de una burguesía urbana que le arrebata la población que sirve de fuerza de trabajo a una oligarquía terrateniente. No se da un proceso cualitativamente diferente de concentración espacial de la población. No surge en la región una concentración de población desligada de la tierra, que verifique la presencia de una nueva "ley de población", innovadora respecto de las leyes de población del modo de producción anterior;

c) La tecnología, que le es incorporada desde el exterior, corresponde a otra fase de desarrollo del modo de producción capitalista. No surge del propio desenvolvimiento autónomo e interno, lo cual indica que no es el fruto de una maduración y desarrollo de las fuerzas productivas. Señalamos este punto que tendrá especial importancia respecto del problema de la correspondencia entre el nivel tecnológico y la estructura del empleo en las haciendas capitalistas. La presencia de este desnivel generará las condiciones propicias para el surgimiento de una intensa sobrepoblación relativa en el agro;

d) Por último, se constata un tipo de capitalismo que no se ha visto forzado a desarrollarse creando su propio mercado, como lo ha hecho la naciente burguesía europea en su época revolucionaria. El mercado le ha sido dado desde fuera con caracteres de marcada rigidez y controlado siempre desde el exterior. Esto afecta, naturalmente, sus posibilidades de expansión y diversificación endógena, que en otras condiciones podría haber aumentado la capacidad de incorporación de mano de obra. Se enfatiza este aspecto como algo de importancia crucial. La limitante proveniente del mercado, específica en los países de tardía incorporación al capitalismo mundial, opera como una variante en el problema de la creación de sobrepoblación relativa que surge a partir de los desajustes tecnológicos ya mencionados.

De lo dicho se puede colegir que el capitalismo agrario que ofrece la región centroamericana, no opera por disolución de las formas de organización de la producción anteriores, sino que se establece con una legalidad propia, debiéndose ajustar a la sociedad preexistente al mantener rasgos suyos importantes. Es esta integración específica la que habría que considerar desde el punto de vista de la incorporación de la fuerza. de trabajo al sistema.

Si se intenta avanzar algo en la materia, diríamos que esa integración específica estará dada por las formas de tenencia de la tierra, las cuales definen un particular modo de relación de los factores de la producción, capital y trabajo, con el principal medio de producción que continúa siendo la tierra. De aquí debieran desprenderse relaciones de producción originales. Lo esencial al respecto, pensamos, lo constituye el hecho de que este capitalismo agrario no desata los vínculos con la tierra. Naturalmente, si el principal medio de producción lo constituye la tierra no parece haber nada de sorprendente en esta afirmación. Pero la situación 
va más allá. La relación con la tlerra no se da sólo en términos de medios de producción. Lo específico de esta forma capitalista, y esto interesa mucho más, es que la propia fuerza de trabajo continúa parcialmente ligada a la tierra. Sin embargo, los lazos que atan al trabajador a la tierra no se dan pura y simplemente como se definen en el régimen feudal; adquieren una elasticidad derivada de la "liberación" y de la predisposición a la movilidad, características del salario como forma esencial de retribución del trabajo en el sistema capitalista. Esto ha sido discutido con amplitud en términos de las relaciones de producción eventualmente surgidas de esta combinación peculiar del agro centroamericano, lo que, al parecer, no ha sido observado es cómo la dialéctica entre el arraigo a la tierra y la liberación contenida en las formas de salario, inciden en los determinantes de la movilidad física, espacial, de la fuerza de trabajo en el agro. Al respecto se propone un esquema de interpretación global de los flujos y reflujos que experimenta la fuerza de trabajo campesina, justamente como efecto de la composición flexible y cambiante entre una forma de trabajo capitalista, esto es, desarraigada, y una forma de trabajo que supone la "inmersión agraria".

El carácter "híbrido" del capitalismo que nos ocupa, se manifiesta en la coexistencia entre un núcleo de carácter marcadamente capitalista, por su relación con el mercado, con el crédito, por su tecnología, y aun por las formas de remuneración al trabajo predominantes, y, por otra parte, un contorno no capitalista que llamaríamos de "usufructo". De aquí resulta una combinación particular entre una economía de mercado y una de subsistencia, combinación que se torna beneficiosa para el sistema como tal, esto es, para la acumulación de capital agrario. Si no contribuyese de manera positiva a la mejor acumulación de capital no podría perdurar; por lo tanto, es por esta vía por donde habría que buscar la racionalidad de este sistema en apariencia desconcertante, lo cual debería ser el paso necesario para la explicación de su estabilidad. En realidad, el núcleo capitalista necesita de un contorno de usufructo a fin de asegu1 arse una mano de obra, in situ, que sea lo suficiente barata y obediente. Para esto, el propietario capitalista la mantiene ligada personalmente a él, dependiendo de él, otorgándole para su usufructo un trozo de tierra de su propiedad, que es recibido por el trabajador como un privilegio concedido, que compromete su gratitud. La mano de obra se vuelve en extremo barata al ser remunerada con tierras para el uso, que son por lo general de mala calidad, o que no proporciona grandes rendimientos sin una fuerte incorporación de capital. No puede haber remuneración más barata que la que se hace con un bien de uso, concedido temporalmente, que constituye un recurso abundante para el propietario, y cuya utilización se realiza regulada y controlada por éste. Por otra parte, el contorno de usufructo compuesto sea por minifundios externos al latifundio capitalista y satelizados por él, sea por parcelas al interior del mismo latifundio, en las que priva una producción de subsistencia, nece- 
sita del núcleo capitalista desde el momento en que los trabajadores que lo habitan, que no alcanzan a subsistir con ese tipo de economía llamada de "subsistencia", deben emplearse allí para redondear un ingreso más decoroso.

La convivencia entre los elementos opuestos que hemos mencionado, se presenta tanto a nivel del complejo latifundio-minifundio que se complementan mutuamente, como a nivel de un régimen de propiedad combinado, en el cual se integran una forma típica de explotación capitalista con otras formas de usufructo originales tales como el colonato, el esquilmo, la aparcería, la mediería y otras. La dualidad entre el núcleo capitalista y su contorno de usufructo se torna beneficiosa para el sistema como tal al conseguir el desvanecimiento de una eventual amenaza de la fuerza de trabajo sobre las condiciones de acumulación. Esto se procura mediante el artificio, que responde por lo demás a tradiciones históricas y culturales, de mantener una zona de economía de subsistencia que disfraza y absorbe el desempleo. Lo que se consigue con esto es abrir una válvula de escape a la presión sobre los salarios. Al nivel de las explotaciones, o de las unidades empresariales, el bajo rendimiento de la economía natural obliga al trabajador a incorporarse, temporal o parcialmente, a la economía capitalista a fin de mejorar su situación. De allí que, en última instancia, el nivel salarial capitalista estará determinado por el ingreso de subsistencia, que necesita, en la práctica, sólo ser un poco superior a éste.

Se han considerado muchísimo estas formas no capitalistas de tenencia o estas relaciones de producción agrarias como formas señoriales decadentes, en proceso de disminución o de extinción. Esto, lo hemos ya dicho, puede ser cierto a muy largo plazo. Pero por lo general no se verifica en períodos más cortos. Incluso en las condiciones peculiares en que se desenvuelve el agro centroamericano, con su racionalidad particular, esta tendencia puede darse o no. Tenemos el caso de El Salvador, el país más industrializado de la región, en donde el colonato, y otras formas de tenencia que no son la propiedad propiamente tal, en vez de disminuir entre los censos de 1950 y 1961, han ascendido de manera brusca,

Cuadro 1

El Salvador: Ténencia de la tieria, 1950-1961 (hectáreas)

\begin{tabular}{lrrr}
\hline Tononcia & 1950 & 1961 & \multicolumn{1}{c}{$\begin{array}{c}\text { Variacion } \\
(8)\end{array}$} \\
\hline Propiotarios & 107875 & 88105 & -18.3 \\
Colonoo & 33384 & 54774 & 64.1 \\
Otros & 32945 & 81408 & 147.1 \\
Total & 174204 & 224267 & 28.8 \\
\hline
\end{tabular}

Fuente: Rafael Menjívar, "Hacia una reforma agraria en El Salvador", La Universidad, Revista bimestral de la Universidad de El Salvador, Año 92, Núm. 4. julio-agosto de 1967. 
lo que confirma la idea de que no se trata de formas señoriales en decadencia sino en plena vigencia y actualidad en el sistema agrario de Centroamérica (véase el cuadro 1 ).

Estos datos pueden ser interpretados como una señal del "atraso" del agro salvadoreño, que en vez de evolucionar involuciona. Creemos que no es así. Lo que sucede es el comportamiento natural de la zona de usufructo, a la que le ha correspondido acrecentarse como respuesta a las fluctuaciones del núcleo capitalista de la agricultura. Un modelo dialéctico de acción y reacción entre el núcleo capitalista y el contorno de usufructo puede rendir mejores resultados en investigaciones destinadas a la mejor comprensión del agro centroamericano.

En la síntesis entre el núcleo capitalista y el contorno de usufructo, el polo capitalista es por necesidad el que subordina al otro. Sin embargo, al nivel de la incorporación de la fuerza de trabajo, puede acontecer una de dos cosas: el predominio efectivo de la retribución capitalista del trabajo, o el predominio de las formas de retribución por usufructo, lo que depende de las relaciones entre la disponibilidad de tierra, por una parte, y los factores que componen la coyuntura económica en el agro, como son las fluctuaciones del mercado, principalmente el externo, las transformaciones tecnológicas, y los intereses competitivos entre sectores diferenciados dentro de las clases dominantes. La concreta conformación de esta síntesis de contrarios, el núcleo y su contorno, por necesidad cambiante y fluctuante, definirá la magnitud y con éste las características de la fuerza de trabajo que necesita incorporar el agro. La propia fuerza de trabajo será, por lo tanto, también variable, y siempre precaria la correspondencia entre el carácter de una forma de producción concreta, sea un tipo de cultivo o la actividad productiva de una región, y el volumen de mano de obra necesitado. Es fácil advertir la importancia que esta inestabilidad del empleo reviste para el estudio de la población agrícola, y en particular de las migraciones internas. La fuerza de trabajo será siempre relativamente móvil, y no podrá extrañar a nadie que deambule sin trasponer los umbrales del sector agrícola.

Para que un sistema como el propuesto pueda funcionar, se requiere el supuesto básico de la existencia efectiva de tierras disponibles, desocupadas o subocupadas. El estudio dirigido por CEPAL, FAO, OIT, IICA, SIECA, OTC y OEA a que nos hemos referido afirma que el $66 \%$ de la superficie territorial de Centroamérica está constituida por tierras vírgenes. ${ }^{10}$ No se puede negar la disponibilidad absoluta de tierras en los países centroamericanos salvo en El Salvador. Pero quizás esto no sea lo más importante. La disponibilidad relativa, debida a la subutilización, es muy elevada, incluso en este país. En Centroamérica sólo $20.6 \%$ de las tierras en fincas se utiliza en cultivos temporales o permanentes, pudiéndose, a juicio de estos organismos, incorporar a este rubro otro $39.3 \%$, o sea aumentarlo casi $200 \%$. Además, se observa que $31.3 \%$ de la tierra en

10 Tenencia de la tierra..., op. cit., p. 25. 
fincas se dedica a actividades económicas marginales, señalándose que este alto porciento se puede deber en parte al hecho de que una porción de esta tierra en fincas se encuentra en la frontera agrícola, o en tierras de bosques vírgenes o de explotación forestal, pero sobre todo a "causas vinculadas con la estructura de la tenencia". Muchas tierras "aptas potencialmente para cultivos anuales intensivos se dedican a explotaciones ganaderas, generalmente extensivas". El $36 \%$ de la tierra utilizada en la región se dedica a la ganadería. Y esto acontece en tierras aptas para cultivos más intensivos, aun cuando la ganadería pudiera relegarse a tierras más apropiadas pero menos aptas para cultivos. La razón de esta subutilización de la tierra, para los autores de este estudio, se debe a que ésta se considera, en gran parte, como un bien de inversión segura, que revalúa el capital invertido sin, o con muy poco costo y que se valoriza con la inflación y con la posible presión sobre la tierra y los recursos que se origina en el crecimiento de la población y en la expansión urbana.11

En el caso de los latifundios, que representan en la región el $38.4 \%$ de las tierras en fincas, y que constituyen las tierras de mejor calidad - las mejor situadas, el uso de la tierra no está determinado por las necesidades sociales, sino por la proporción que se obtiene entre la ganancia privada que produce una inversión, y el monto y riesgo de la propia inversión, pudiendo ser, y con frecuencia lo es, más rentable al propietario una tierra subutilizada que una tierra plenamente explotada.

Nada extrañaría que la subutilización de la tierra vaya aparejada con desempleo de la fuerza de trabajo. El citado estudio dirigido por la CEPAL pretende dar cuenta de la retención en el agro de mano de obra excedente observada en las explotaciones menores. Pero señala al mismo tiempo, al cuantificar el fenómeno, una norme capacidad de absorción en las explotaciones mayores. Al suponer una adecuada utilización de la tierra, se obtiene una proporción asombrosa entre mano de obra requerida y disponible en las fincas. Tomemos como ejemplo el caso de Costa Rica. Allí las fincas subfamiliares (menores de diez hectáreas) registran una relación de un trabajador requerido por dos disponibles, o sea un $100 \%$ de excedente. Pero en las fincas multifamiliares grandes (mayores de 500 hectáreas) la proporción es de un trabajador disponible por 25 requeridos (un déficit de mano de obra de $96 \%$ ). Por otra parte, la estimación que el estudio hace del desempleo agrícola real, al utilizar el mismo criterio de la diferencia entre los trabajadores requeridos y los trabajadores disponibles, llega a $3.2 \%$ para Costa Rica, $28 \%$ para Nicaragua, y $54 \%$ para El Salvador. Lo que queda bien claro para CEPAL y los otros organismos es que el desempleo se debe a la estructura que adopta en la región la tenencia y la utilización de la tierra.

La disponibilidad real de tierras, absoluta o relativa, unida al excedente de población agrícola, son los factores que en su combinación vuel-

11 Tenencia de la tierra..., op. cit., p. 29. 
ven rentable un esquema de producción basado en la propiedad privada, y definido por la articulación, que varía según el provecho resultante para los grandes propietarios, entre un núcleo capitalista, de alta productividad y alta tecnología orientado por lo general al mercado externo, y un contorno de usufructo que liga de forma inestable y móvil una fuerza de trabajo abundante a una tierra subutilizada. El sistema de tenencia de la tierra en Centroamérica, calificado como semifeudal o señorial, o en forma genérica como precapitalista, se revela, desde el punto de vista histórico, como el producto de esta combinación de factores: abundancia de tierras y abundancia de mano de obra agrícola, dentro de un marco global de producción para el mercado externo que coarta las posibilidades de expansión endógena. Pero se convierte de inmediato en un elemento institucional, en un factor decisivo desde el punto de vista social y aun político, que mantiene, estabiliza y perpetúa una situación extrema de subutilización de la tierra unida a un desmesurado desempleo agrícola. No hay ninguna paradoja en lo afirmado; responde a la lógica más estricta de un sistema de apropiación privada de los recursos dentro de un contexto de propiedad latifundista. La activación de los recursos no dependerá de las necesidades de las grandes mayorías ni de los requerimientos globales de la economía, sino de los intereses de estos sectores dominantes, que pueden constituir el $5.5 \%$ de la población rural si se toma en cuenta los propietarios de 50 o más hectáreas, o el $0.48 \%$ si se considera a los propietarios de 500 o más hectáreas. ${ }^{12}$

Diríamos, para finalizar esta primera parte, que la integración del núcleo capitalista con el contorno de usufructo, sea a nivel del sistema global (lo que abriría la posibilidad de comprenderlo como la articulación de dos modos de producción en uno específico), sea a nivel de las unidades empresariales agrícolas, es la característica central del capitalismo agrario centroamericano, a partir de la cual se pueden comprender en un todo homogéneo y estucturado los otros rasgos particulares de este sistema que definen una organización social de la producción de carácter específico, con su propia división del trabajo. La subutilización de la tierra unida a la superabundancia de fuerza de trabajo agrícola, corresponden a una particular estructura de tenencia de la tierra, que a su vez, opera en forma proporcionada a la rigidez del mercado externo, que es el factor dinamizador, o paralizante, del capitalismo agrario regional. La comprensión de la lógica que comanda el funcionamiento del sistema agrario serâ de vital importancia para intentar la explicación de los problemas de población en el sector. Al respecto, es de singular importancia la explicación de la razón de ser, dentro de este sistema, de la formación de una creciente sobrepoblación relativa.

12 Tenencia de la tierra..., op. cit., p. 183. 


\section{LA SOBRÉPOBLACIÓN RELATIVA EN EL AGRO CENTROAMERICANO}

En países, atípicos por cierto, como El Salvador con una densidad demográfica de 153 personas por kilómetro cuadrado, el crecimiento de la población es de $2.8 \%$ anual durante el último período intercensal. Este crecimiento no podría dejar de constituirse en factor importante para el análisis de las migraciones. No obstante, la cuestión no resulta tan obvia. El conocimiento de este solo dato, crecimiento de la población y densidad de la misma, podría conducirnos a la siguiente interpretación. Que dentro de una población sobresaturada, que crece a un ritmo violento, la tendencia en los desplazamientos de la población debería darse desde las regiones de más elevada densidad hacia regiones de densidad más baja. Sin embargo, esta hipótesis no se ajusta a los datos. La migración en El Salvador tiene como destino los departamentos de San Salvador, La Libertad, Sonsonate y La Unión, que se encuentran entre las regiones más densamente pobladas. ${ }^{13}$ Esto no se debe a particularidades del caso salvadoreño que presenta una cierta singularidad dentro de la región. Tomemos el caso de Costa Rica que puede ilustrar de la misma manera. Aquí se observa la siguiente dirección en los desplazamientos de la población: antes de 1950, como fecha más tardía, se dirigen desde la meseta central, la región más densamente poblada del país, hacia las llanuras costeras, escasamente pobladas; sin embargo, con posterioridad a esa fecha la corriente cambia completamente de dirección y describe un movimiento contrario que se orienta desde las zonas bajas, que continúan siendo de escasa densidad, hacia la meseta central que tampoco ha disminuido su nivel de densidad. El cambio no se podría explicar como saturación del lugar de destino de la corriente, pues no se alteran en lo fundamental las relaciones de densidad.

Podemos concluir que la variable densidad de población no opera como determinante esencial en el movimiento migratorio. Tampoco el crecimiento de la población lo podría ser en sí mismo, esto es, aislado de otros factores que lo tornan problemático. Ya nos hemos referido a la abismal subutilización de los recursos en la región correlativa a la inmensa "capacidad ociosa" de la economía agraria centroamericana, que con una adecuada activación podría proporcionar tanto el trabajo como los productos que una población necesita para reproducir y mejorar sus condiciones de vida. Por lo tanto, y en tales circunstancias, el crecimiento de la población no puede significar por sí un problema que pueda ser

13 Los datos que atestiguan esta afirmación están en proceso de elaboración por el equipo de investigación sobre Población, Desarrollo Rural y Migraciones Internas en Centroamérica. Aunque para El Salvador no se puedan captar censalmente las corrientes migratorias, en términos de lugar de origen y lugar de destino, sí se pueden definir esos departamentos como los que atraen población en el país y los diez restantes, como de expulsión. Esto, por lo menos, según el censo de 1961. 
resuelto, ni siquiera en parte, por la migración. Al contrario, en muchas regiones lo que hace la migración es agudizarlo, como se' podría suponer en el caso de migración campo-ciudad.

Esto lleva a preguntar acerca de las circunstancias que hacen que el crecimiento de la población se torne una causal de migración. Es probable que esto se da en lo fundamental en dos situaciones. Primero, cuando tiene lugar en zonas en que impera una estructura de propiedad de la tierra basada en el minifundio. Aquí, el crecimiento demográfico actúa en combinación con el deterioro de las tierras, generalmente de la peor calidad, que se erosionan debido al uso intensivo, no diversificado y practicado con procedimientos primitivos. La pequeña parcela que mal puede sostener a dos personas no es capaz de sostener a cuatro. Los trabajadores sobrantes deben abandonar sus comunidades y buscar otros horizontes. En segundo lugar, cuando el crecimiento demográfico se localiza en regiones en donde priva el latifundio de tipo capitalista, explotados con métodos altamente tecnificados. En este caso es el propio desarrollo y no el subdesarrollo el factor determinante que vuelve problemático el crecimiento de la población. Son los trabajadores expulsados por las máquinas los que deben emigrar. Estas dos situaciones se pueden ilustrar con ejemplos tomados de la realidad centroamericana. Una región típica de gran presión demográfica sobre la tierra es el altiplano guatemalteco, que muestra un aumento poblacional de $3 \%$ anual, y que cuenta con una media de 1.1 hectárea de tierra cultivable por parcela, la mayor parte con fuertes pendientes. Estas tierras sólo pueden dar ocupación a 10\% de la mano de obra disponible (mano de obra familiar), aun tomando en cuenta los bajos niveles tecnológicos. ${ }^{14}$ Este punto está lo suficiente desarrollado en el estudio de S. Barraclough y A. Domike sobre la estructura agraria de siete países latinoamericanos. Respecto del segundo caso, una zona de latifundio tecnificado en donde el crecimiento de la población se traduce en una intensificación del flujo migratorio, tenemos la provincia ganadera de Guanacaste en Costa Rica, la zona de mayor expulsión de población del país. Allí el incremento demográfico no entra en contradicción con la disponibilidad de tierras por familia, que supera en la mayoría de los cantones las 100 hectáreas. ${ }^{15}$ La razón de la migración proviene, obviamente, de las relaciones tecnológicas imperantes.

A este propósito, concordamos plenamente con la afirmación de Paulo Singer, para quien la correspondencia entre el crecimiento demográfico y la intensidad de los cultivos, con la transformación de los métodos agrícolas, que concuerda en el caso de estar orientada a la absorción de

14 Saúl Osorio y Bernardo Lemus, Trabajo presentado al Seminario sobre Población y Desarrollo, Guatemala, agosto de 1968.

15 Carlos Raabe, "Estructura agraria y migración. Un intento de análisis", Trabajo presentado al Seminario Interno de la Investigación sobre Población, Desarrollo Rural y Migraciones Internas en Centroamérica, agosto de 1974. 
mano de obra, no se logra por obstáculos de tipo institucional. Resulta obvio que si la tierra es propiedad privada y está distribuida en forma desigual, la presión demográfica sobre la tierra será idénticamente desigual. Incluso, como acabamos de observar, esta presión debe traducirse principalmente sobre el minifundio. Pero también puede verificarse en regiones de latifundio debido a las relaciones tecnológicas que vuelven escasa, en la práctica, una tierra que puede ser superabundante. En estas condiciones nada podría obligar al propietario a emplear la fuerza de trabajo adicional generada de manera principal por el crecimiento demográfico. Como lo sostiene Singer, esta fuerza de trabajo desempleada busca colocación en la pequeña propiedad, al producir mayor saturación de la población, emigra, busca trabajos temporales, o por último se dirige a las ciudades. ${ }^{16}$

En las circunstancias imperantes en Centroamérica, el mero crecimiento de la población, por intenso que sea, no constituye por sí solo un fenómeno que atente contra la convivencia social al obligar a las personas a abandonar sus comunidades de origen. Pero sí lo resulta cuando transcurre al interior de una organización social de la producción que excluye a grandes contingentes de mano de obra, tanto de una incorporación deseada al sistema productivo, como al propio sistema de consumo. Lo que acontece en este caso es estrictamente la formación de una superpoblación relativa.

En América Latina esta problemática ha sido abordada por diversos autores, aunque principalmente desde una perspectiva urbana, y muchas veces de una manera un tanto abstracta y formal. ${ }^{17} \mathrm{La}$ evidencia de una

16 Paulo Singer, Dinámica de población y desarrollo, México, Siglo XXI Editores, 1971 , pp. 88-89.

$17 \mathrm{El}$ empleo del término marginalidad muestra una variedad considerable en sociología. Al seguir el estudio de Pedro Parra Sandoval acerca de la marginalidad y el desarrollo, podemos distinguir al menos tres enfoques diferentes. En primer lugar, el sentido que cobrd en autores norteamericanos, que se refieren más específicamente al "hombre marginal", en tanto individuo que no pertenece a ninguna cultura; también se encuentra la corriente que ha estudiado la "cultura de la pobreza", desde una perspectiva más bien antropológica y bastante condicionada por el problema racial. La perspectiva teórica predominante lleva a considerar la marginalidad como un fenómeno de minorías, no adaptadas lo suficiente, por lo cual su validez para la investigación del problema en un contexto latinoamericano se ve bastante restringida. En segundo término, se podrían agrupar una serie de estudios vinculados en CEPAL e ILPES, que han partido en lo fundamental del fenómeno ecológico de tugurios y barrios miserables que han proliferado en los últimos decenios; la perspectiva es básicamente urbana. El enfoque se orienta, desde un punto de vista estructural, hacia el problema del empleo y el desempleo, al utilizar una serie de variables tales como la sindicalización, el nivel salarial, el estatus ocupacional, la estabilidad del empleo, pero todo esto presidido por la ubicación ecológica que actúa como factor discriminante aislando la población propiamente marginal de la no marginal. Tenemos, por último, los estudios que se han realizado en DESAL. Éstos también parten del factor ecológico, aunque éste resiste una considerable ampliación que lo hace incorporar el mundo rural. Para DESAL, "la 
gran masa sobrante, que se ha concentrado en la periferia de las principales ciudades latinoamericanas, ha llevado a muchos científicos sociales a plantearse el problema de la "marginalidad", en cuanto constituye un fenómeno alarmante. Se constata que el contingente de fuerza de trabajo desplazada del sistema se torna creciente, sin que se vean aparecer a mediano plazo mecanismos integradores. Sin embargo, no resulta arriesgado afirmar que es bastante poco lo que se ha avanzado en la comprensión concreta e histórica de este fenómeno; no es mucho lo que se ha aclarado respecto de las circunstancias que han rodeado su surgimiento. El debate se ha centrado en esencia en los problemas de conceptualización. Se ha discutido bastante acerca de si esta cuantiosa masa sobrante deba o no ser entendida como un "ejército industrial de reserva", si sea $\alpha$ no un rasgo típico y general del desarrollo del capitalismo. No se podría negar de plano la pertinencia de una discusión entablada por los más eminentes sociólogos del continente, sin embargo, estimamos que ha permanecido un tanto formal, desviándose la atención, y de esa manera los recursos y los esfuerzos, de un estudio más concreto del fenómeno de la marginalidad. ${ }^{18}$ Se ha debatido más acerca del significado y el contenido que el ejército industrial de reserva cobra en los escritos de Marx, que acerca de las condiciones que definen la coyuntura histórica en que esta masa sobrante surge en América Latina. Por ejemplo, no deja de ser significativo que la llamada masa marginal se haya vuelto al menos visible alrededor de los años cincuentas, en circunstancias en que el capitalismo cumple en la región una existencia de más de un siglo. ${ }^{19}$ Hechos como éste, quizás entre muchos otros, no han servido de derroteros para inves-

médula del concepto de marginalidad consiste en una falta de participación de diversos ordenes, acompañada de la imposibilidad de parte de los marginales para poner fin a esta falta de participación por incapacidad de organización interna". En realidad, lo que no logra captar DESAL es que "la falta de participación de un sector dominado, es menos función de su incapacidad orgánica que de la capacidad de organización del grupo dominante". Acerca de la caracterización de estas corrientes y los autores que comprenden, se puede consultar el trabajo de Rodrigo Parra Sandoval: "Marginalidad y subdesarrollo", en Las migraciones internas, Bogotá, Colombia, ASCOFAME, 1970. Otra dimensión adquiere el problema a partir del artículo de José Nun, "Superpoblación relativa, ejército industrial de reserva y masa marginal", publicado en 1969 en la Revista Latinoamericana de Sociología. Se inicia entonces una discusión acerca de la conceptualización marxista del fenómeno de la marginalidad. Sin embargo, es en ese momento, que auguraba la posibilidad de una comprensión estructural e histórica del problema, cuando el debate se torna más exegético y formal. No se podría negar que la discusión ha aportado sobre los aspectos estructurales del problema, pero todo esto dentro de un marco fuertemente escolástico.

18 Al respecto se pueden apreciar las repercusiones que han tenido en el ámbito. académico los artículos que componen la polémica sostenida por José Nun y Fernando $\mathrm{H}$. Cardoso, discusión que quizá contra la voluntad de los autores ha tomado un carácter casi puramente formal.

19 La observación ha sido desarrollada por Paulo Campanario en su trabajo discutido en el Seminario Interno sobre Población y Desarrollo Económico, promovido por el Programa Centroamericano de Ciencias Sociales del csucA. 
tigaciones destinadas a entender las coyunturas reales en que se desen. vuelve la estructura del empleo en América Latina.

En estas páginas no intentaremos un análisis al respecto, desbordaría tanto nuestros objetivos particulares como nuestras posibilidades. Sin embargo, desearíamos detenernos un tanto en la cuestión y centrar la atención sobre algunos aspectos del fenómeno, sobre todo en la medida en que puede constatarse en el agro.

En primer lugar, habría que señalar que las principales conceptualizaciones del problema de la marginalidad, lo comprenden antes que nada como un efecto de "la revolución tecnológica" en las relaciones de producción. ${ }^{20} \mathrm{El}$ desarrollo tecnológico, aportado a la periferia desde los centros más desarrollados, opera negativamente sobre la mano de obra que pasa a ser una población sobrante respecto de la capacidad de absorción del mercado de trabajo. El modelo subyacente al análisis es, obviamente, el de la acumulación capitalista con su dinámica de crecimiento relativo del capital constante respecto del capital variable, o la disminución relativa de este último por el aumento en la composición orgánica del capital. Sin embargo, para Quijano, la diferencia del fenómeno "marginal" respecto del modelo clásico marxista del ejército industrial de reserva radica en lo siguiente: este modelo, tal como lo concibe Marx, corresponde a una etapa del desarrollo capitalista, en la cual se generan períodos de crisis en el mercado de trabajo, pero crisis de tal naturaleza que dejan abierta la posibilidad para que el excedente de mano de obra sea reincorporado en un nuevo ciclo económico. Esto es así porque la capacidad productiva del sistema, y aun de los mecanismos de acumulación, está basada en la explotación del trabajo obrero. En la actualidad el esquema del ejército industrial de reserva deja de funcionar al cambiar las circunstancias que fundamentan la acumulación de capital. Ahora la expansión de la capacidad productiva del sistema reposa más que en el trabajo de los obreros, en el desarrollo tecnológico. La mano de obra va quedando definitivamente desplazada, al ver que se le niega la eventualidad de una reincorporación de carácter estable al sistema. Queda fuera del mercado de trabajo.

Sin negar la justeza de la afirmación de Quijano, parece que el problema es más complejo, sobre todo si se incorpora la pregunta acerca de la naturaleza del desempleo rural, que es el que intensifica el desempleo urbano. En realidad no se puede comprender este último sin conocer las causas que provocan el primero. Es aquí donde el modelo teórico tiene que hacerse más flexible. En realidad, el desempleo rural no se debe, por necesidad al avance tecnológico, esto es, a la reducción del capital variable a costa del capital constante. En las explotaciones agrarias de carácter claramente capitalista esto puede acontecer. Pero no es la única

20 Aníbal Quijano, "Redefinición de la dependencia y proceso de marginalización en América Latina”, América Latina, dependencia y subdesarrollo, San José, Costa Rica, Editorial Universitaria Centroamericana, 1973. 
causal de desempleo rural. Este desempleo no es siempre, ni en la mayoría de los casos, quizás, producto de las relaciones capitalistas de producción, aunque sea efecto del avance del capitalismo en la agricultura. La masa de campesinos que emigra hacia las ciudades o que se desplaza buscando trabajo en el agro procede, en parte, de zonas de explotación capitalista en donde se podría aplicar la concepción analizada, pero también en parte, de zonas de economía natural. Es esto último lo que debería llevar a buscar una explicación más amplia, al mismo tiempo que más concreta, al problema de la marginalidad, tanto urbana como rural.

En segundo lugar, habría que distinguir con precisión dos cosas bien distintas: por una parte, un fenómeno de expulsión de mano de obra, debido en esencia a causas del tipo de las apuntadas por Quijano y, por otra, un fenómeno de no absorción, que debe tener otras raíces. Como se ha observado antes, la penetración capitalista en el agro centroamericano no ha desplazado del todo las relaciones de producción que la han antecedido, sino que las ha mantenido, combinándose con ellas en una proporción bastante significativa. El economista brasileño Carlos Lessa ha señalado teóricamente la distinción entre lo que él llama la "marginalización por no incorporación", que habría que aplicar de manera fundamental al agro, y la "marginalización por rechazo" que podríamos esperar en la economía urbana y en las áreas capitalistas de la economía agraria. ${ }^{21}$ Según Lessa, la primera se da en la etapa de producción primaria para la exportación, cuando la población heredada del período colonial permanece, en buena parte, ajena a la economía agroexportadora.

Las proposiciones que se han planteado respecto del funcionamiento del capitalismo agrario centroamericano, permiten apreciar el interés de estudiar las combinaciones que se pueden presentar entre ambas formas de marginalidad, a fin de explicarnos la población excedente en el agro. Creemos que en las zonas eminentemente minifundistas, por lo general zonas de fuerte expulsión de población, la emigración no corresponde a una marginalización capitalista, aunque tenga que ver con la penetración de las formas capitalistas en el agro. Es una marginalización que se debe a una incapacidad del sistema total para absorver la mano de obra, y que se explica tanto por las formas de tenencia de la tierra que sustentan toda una economía agraria, como por la naturaleza del desarrollo urbano-industrial respetuoso de los intereses agrarios. En cambio, en las zonas agrarias de economía básicamente capitalista, encontramos operando ambos factores de marginalización, tanto una expulsión de población por obra de la mecanización agrícola, como una "no incorporación" en los sectores de usufructo que habitan los propios latifundios de explotación para el mercado externo. La marginalidad es combinada, no sólo en el agro como sistema, sino en las mismas unidades de explotación

21 Carlos Lessa, "Marginalidad y proceso de marginalización", América Latina, dependencia y subdesarrollo, San José de Costa Rica, Editorial Universitaria Centroamericana, 1973. 
agrícola. Además, la incorporación a la economía capitalista de la fuerza de trabajo agrícola es muchas veces parcial o temporal, lo que da cuenta de la dificultad, lo mismo que de la necesidad, de aislar y definir científicamente el fenómeno en el agro.

En tercer lugar, sería muy interesante aplicar al agro centroamericano la reflexión que Quijano se hace respecto de las "funciones", o, para evitar falsas interpretaciones, la razón de ser del ejército.industrial de reserva, en contraposición a la naturaleza para él específica de la "masa marginal", observada en América Latina. Para este autor, las funciones del ejército industrial de reserva son dos: la función propiamente de reserva y la función salarial. La función de reserva, que se cumplía en el capitalismo anterior a la revolución tecnológica, cuando la mano de obra antes desplazada era requerida por el sistema que entraba en un nuevo ciclo económico, no se podría dar en la situación nueva que se ha creado en América Latina. Esto no es posible en virtud de que los aumentos en la producción se consiguen en la actualidad sólo por medio del progreso técnico. La función salarial, esto es, la acción sobre el descenso de los salarios industriales que el peligro de inmediato reemplazo significa para la presión obrera, se sigue dando pero parcialmente. Se verifica en las empresas de bajo nivel tecnológico, en donde el fácil reemplazo de los obreros sigue siendo una amenaza real. Pero no tiene por qué darse en las empresas de alto desarrollo tecnológico, ya que allí el personal ocupado cuenta con una mayor calificación, lo que explica la mayor dificultad en su reposición, con lo cual el nivel salarial es relativamente más alto, no necesitándose que sea constantemente deprimido.

Creemos que en el agro centroamericano la primera de estas "funciones" no es realmente aplicable, aunque por motivos un tanto diferentes a los mencionados por Quijano. ${ }^{22}$ No es sólo el desarrollo tecnológico lo que margina a la fuerza de trabajo campesina, sino la división social del trabajo que impone un régimen de control privado sobre la tierra. La propia expulsión tecnológica, por decirlo así, se apoya en las formas de tenencia y en la privatización de los recursos, con evidente daño para el conjunto de la población. Sólo en la medida en que se vuelve escaso un recurso tan abundante como la tierra, es posible implantar determinados patrones tecnológicos. Respecto de la segunda función, es difícil sostener la afirmación de Quijano en el sentido de que la masa marginal campesina no cumpla con el cometido de reducir el nivel de los salarios agrícolas. Más adelante tendremos ocasión de referirnos a la "racionalidad" que, dentro del capitalismo agrario centroamericano, cobra un sistema de organización del trabajo que reposa sobre la subutilización de la tierra y sobre el desempleo agrícola. Pero la sobreabundancia de la mano de obra campesina juega, entre otros, ese papel particular de deprimir los salarios, sobre todo en ausencia de organizaciones sindicales campesinas que puedan luchar por una mejora económica, condición verifica-

22 Aníbal Quijano, op. cit., p. 190 ss. 
da con amplitud en la región. Por lo tanto, se puede concluir, la "marginalidad" campesina es de tal magnitud, en relación a las tendencias imperantes de absorción de mano de obra en la economía agraria, que no existe una posibilidad franca de incorporación. Por otra parte, esta superabundancia de fuerza de trabajo actúa en beneficio del gran propietario en términos de asegurarle mano de obra barata y obediente.

En cuarto lugar, habría que intentar una caracterización provisional de la "marginalidad" campesina, a fin de determinar las variables y los indicadores que deberían intervenir en una investigación concreta sobre la materia. Parece que el rasgo que primero salta a la vista es el elemento de no incorporación significativa a la agricultura comercial, lo que daría oportunidad de aislar una "economía agraria marginal". Pero aquí no se puede ser muy tajante, ya que por lo común el campesino sumido en una economía natural vende parte de la producción, la que excede de su consumo, pero lo hace a través de mecanismos de mercado elementales. El análisis de estos mecanismos de mercado, justamente, es una variable significativa para nuestros propósitos. Sin embargo, quedaría aún mucho por hacer. Según un estudio de Antonio García, ${ }^{23}$ la gama social existente en el agro latinoamericano es amplísima. Comprende las formas más indigentes de actividad agrícola, tales como los campesinos minifundistas, tanto como lo que él llama acertadamente "las formas arcaicas de inmersión campesina", que agrupan formas como el colonato, la aparcería, el inquilinaje, el esquilmo y otras prácticas de tenencia no capitalistas. Entre ambos términos se dan muchas formas intermedias. La marginalidad, que comprende estas situaciones diferentes, debiera definirse de manera principal por las relaciones de propiedad y las relaciones de producción que aquí cristalizan. Sin embargo, para este autor, existen otros aspectos, no menos importantes, que configuran una situación real de marginalidad en el agro. El hecho de que no existan canales de acceso a la tierra, por las características casi señoriales de la propiedad rural, impide todo proceso de movilidad social, y con ello toda posibilidad, por remota que sea, de transformación social. Además, los campesinos se encuentran casi del todo marginados de la cultura, posiblemente a causa de ese mismo aislamiento e inmersión determinados por las relaciones de producción. Menos podría esperarse que existan mecanismos de participación sindical y política, ya que la representatividad política sólo le cabe al propietario de la gran hacienda, nunca al trabajador rural ni al propietario minifundista. Los sindicatos campesinos son o completamente inexistentes o en extremo débiles, por lo que las probabilidades de regateo son nulas en la práctica. Por último, el campesinado en su conjunto carece de mecanismos que le permitan el acceso a los recursos asistenciales del Estado, en especial los que le posibilitarían una asistencia financiera o tecnológica. El propio trabajador agrícola asimilable al proleta-

${ }_{23}$ Antonio García, Sociología de la reforma agraria, Barcelona, Amorrortu, 1973, pp. 93-99. 
rio, el trabajador sin tierras contratado por un salario, paticipa de la llamada inmersión campesina definida por la ausencia de mecanismos de regateo, de participación y de movilidad social. Para García, su salario es marginal, en la medida en que se regula al interior de un mercado rural de trabajo, en donde no existen las pautas de negociación y de intercambio de valores propio del mercado capitalista. No se aplican tampoco, aun en el caso de existir, las normas constitutivas de un derecho laboral de protección al campesino. En última instancia, el límite entre el campesino marginal, de economía de subsistencia, y el peón integrado a una empresa agrícola capitalista, no es muy preciso. Ni uno ni otro, ni ambos en conjunto, pueden constituir una fuerza social capaz de entrar a terciar en la disputa de intereses económicos. Su peso como clase es muy reducido. La tarea científica debería consistir, en este momento, en aislar algunas formas típicas de economía campesina y establecer las vinculaciones existentes entre ellas. Esto revela la existencia de caminos aún no transitados en Centroamérica, que podrían seguir las investigaciones sobre la marginalidad agraria. Tal esfuerzo debería movilizar tanto los aspectos más propiamente económicos, esto es, las relaciones de propiedad y de producción, como los elementos de carácter político e ideológico que estabilizan de manera institucional la marginación de una gran masa campesina.

En último término, correspondería referirnos a la razón de ser, la funcionalidad, o quizás la racionalidad última de esta marginalidad campesina. En la medida en que se trata de un fenómeno generalizado en toda América Latina, que persiste en el tiempo y coexiste con prácticas tecnológicas avanzadas, debería obedecer a alguna lógica del sistema que vuelva racional una aparente irracionalidad. Al respecto, se ha sostenido bastante la tesis de que el empresario agrícola latinoamericano no comparte las normas de trabajo vigentes, tanto en el sistema capitalista como en el sistema socialista, acerca de la productividad creciente y el imperativo de expansión. Su "pusilanimidad" se debería fundamentalmente a la vigencia de esquemas mentales de carácter señorial que lo harían buscar antes que nada el prestigio que le da la propiedad agraria, el consumo suntuario y la autoridad patriarcal ante sus sometidos. No cabría dentro de sus intereses más caros perseguir la multiplicación creciente de las ganancias ni de los recursos. Sin discutir el hecho en sí mismo, que debería aplicarse a un sector de los empresarios agrícolas, parece que esta tesis, que sostienen eminentes estudiosos del agro latinoamericano, carece de carácter explicativo. Lo que hace es sólo posponer la pregunta acerca del porqué. A qué se puede deber la persistencia de esos patrones no capitalistas dentro de una economía que es en lo básico capitalista.

No cabe duda acerca del papel preponderante que juegan la rigidez y la inmovilidad de las estructuras campesinas, basadas en el arraigo del trabajador, a la tierra lo cual, como hemos visto, se presenta tanto en el minifundio como en la hacienda capitalista tradicional. Esto tiene que afectar de manera sensible a la formación de un mercado rural de tra- 
bajo. Sin embargo, para entender la lógica de este sistema habría que interrogarse acerca de la eventualidad de que la aparente irracionalidad se convierta realmente en la máxima racionalidad para los sectores sociales que controlan este sistema. La pregunta debe orientarse hacia la cuestión de cuáles son los sectores perjudicados por esta política y cuáles pueden ser los sectores beneficiados. Desde esta perspectiva habría que indagar sobre la subutilización de la tierra y la creación de una sobrepoblación campesina, sobre la restricción ostensible del empleo y la ausencia de una práctica intensiva en la agricultura. A este respecto Paulo Singer afirma que un elemento que explica esta política restrictiva del empleo por parte de los propietarios latifundistas, procede justamente de los lazos personales del trabajador con el propietario, que convierte el empleo en un "privilegio concedido". El monopolio de la tierra, que implica, como señala otro autor, la capacidad de obligar a otros a hacer lo que uno desea que hagan, sostiene todo el orden jerárquico de la sociedad rural, quedando muy en claro quién decide y quién obedece. Una escasez de mano de obra pondría en peligro la dominación social misma. ${ }^{24}$ Sobre esto existe una apreciable coincidencia de muchos autores. "La preservación del poder social y económico del hacendado exige un nivel mínimo de empleo, rendimiento bajo y situación insegura." 25

Por otra parte, la utilización de métodos intensivos en la agricultura ofrecería a los empresarios dos alternativas únicas, o bien se hace por un aumento de la fuerza de trabajo, o bien por intermedio de la mecanización agrícola. En el primer caso, esto es, excluida la mecanización agrícola, las consecuencias podrían ser de dos tipos: primero, los salarios subirían de manera drástica con lo que los trabajadores adquieren una capacidad de negociación que haría peligrar sin duda la hegemonía absoluta del gran propietario; segundo, la intensificación de la actividad agrícola sin la correspondiente mecanización, requiere de un aumento del tiempo de trabajo que en proporción es mayor al aumento resultante en el producto. "Este tipo de sustitución de factores (tierra por trabajo) acarrea rendimientos decrecientes." ${ }^{26}$ Aunque la productividad de la tierra aumente, desciende la del trabajo. En términos menos técnicos, al propietario no le compensa en ganancias la inversión que ha hecho en la contratación mayor de mano de obra. Por lo tanto, desde un punto de vista económico, además del político, este tipo de intensificación de los cultivos no puede ser conveniente ni racional para el gran propietario. La alternativa válida que le queda no puede ser otra que la mecanización, con lo cual procura un aumento sustancial de la productividad y agudiza la situación crónica de desempleo.

Pero aun si no consideramos los aumentos de la productividad, cuan-

24 Paulo Singer, op. cit., pp. 88-89.

25 Solón Barraclough y Arthur Domike, La estructura agraria en 7 paises de América Latina, Santiago, Icira.

${ }^{26}$ Paulo Singer, op. cit., pp. 75-84. 
do se dispone de mucha tierra los rendimientos de las cosechas, por más subutilizada que esté la tierra, procuran un ingreso generalmente muy alto para el propietario. Si son muy bajos los rendimientos por hectárea, son siempre muy altos los rendimientos totales. Este hecho que parece obvio es de singular importancia. Es perfectamente adecuado a los intereses del gran propietario, quien toma las decisiones en lo que respecta a la producción. "Sin embargo, desde el punto de vista de los campesinos y de la economía como un todo, la actual subutilización de la tierra implica menos alimentos y menos ocupación rural." ${ }^{27}$ Otra cosa acontecería si la tierra fuese un recurso escaso, pero "en las haciendas controladas por la élite terrateniente hay mucha más tierra de la que podría cultivarse. No puede esperarse que ésta mejore sus prácticas administrativas; requeriría toda su dedicación y la reinversión de ganancias a objeto de incrementar la superficie cultivada además de una identificación con la comunidad agrícola. Como esto implicaría mayor ocupación de la fuerza de trabajo, con mayores salarios y mejores condiciones, se opondría a su estrategia de conservar una fuerza de trabajo barata y sumisa, parcialmente desocupada". ${ }^{28}$

La marginalidad agraria, por lo tanto, no puede ser pensada como un simple residuo vergonzoso, como una lacra oculta que se desea eliminar; tampoco se la podría conceptualizar como una mera contradicción del sistema, insuperable y esencial al mismo, y de esa manera una contradicción cuasi escatológica. Al señalarla como contradicción del sistema, habría que intentar recuperar el carácter dialéctico de la contradicción, en el sentido de incluir, de manera conjunta, el elemento de oposición y el elemento de identificación, la racionalidad que da cuenta de la coherencia interna, a la par de la irracionalidad que subraya las consecuencias contradictorias. Estas consecuencias han sido enfatizadas lo suficiente, por lo que destacamos ahora su aspecto de necesidad. $\mathrm{Y}$ en este sentido la sobrepoblación en el agro es una real necesidad, cumple con una función. Los obstáculos estructurales que impiden la expansión del empleo se basan en los factores que vuelven más dinámica la agricultura para los grandes terratenientes; su orientación al mercado externo, que limita las potencialidades autónomas de expansión, y el régimen de tenencia, como la base institucional en que reposa todo el mecanismo de acumulación de capital en el agro. Sobre estos dos soportes se construye toda la economía del desempleo. Luego surgen algunas condiciones que la materializan y tornan realmente necesaria la manutención de una masa campesina sobrante dentro o en la periferia de la explotación agrícola. Entre estas condiciones destaca la abundancia relativa de tierras, ya que una verdadera escasez obligaría a una política de intensificación de los cultivos; la "instrumentalización" de la propie-

27 Ernest Feder, Violencia y despojo del campesinado: El latifundio en América Latina, México, Siglo XXI Editores, 1972, p. 66.

28 Ibid., p. 69. 
dad agropecuaria como mecanismo por excelencia de expropiación y de control social, asimilable a la acumulación originaria que posibilita la apropiación del trabajo ajeno; la hegemonía política del sector terrateniente en virtud de la cual dispone del control del Estado, con lo que neutraliza el surgimiento de condiciones de progreso social que le enajenarían al terrateniente una fuerza de trabajo barata y sumisa. Estos factores crean las circunstancias propicias para una economía del desempleo, esto es, una economía que se mantiene y se desarrolla gracias al desempleo o el subdesempleo. Estos caracteres parecen presentarse en Centroamérica con tintes muy marcados. El problema de la marginalidad, que quizás no aparece tan visible como lo ha sido en otros países de América Latina, se sitúa, creemos, todavía en el campo. Un estudio acerca de la población y sobrepoblación en la región debería comenzar por la cuantificación y el análisis de la población y sobrepoblación en el campo, que cuando llega a grados elevados se trasplanta hacia las ciudades y aparece como un fenómeno de preocupación para cualquier vecino. ${ }^{29}$

\section{Conclusiones Para El estudio de la población}

De lo que hemos observado respecto de la estructura agraria, se pueden sacar algunas conclusiones referentes a estudios más pormenorizados del fenómeno que nos ocupa. La evolución de la economía agraria centroamericana permite detectar cómo el desarrollo capitalista en el agro dinamiza ciertas regiones relegando otras a condiciones mínimas de existencia, al mismo tiempo de generar desempleo crónico, estimado como un rasgo intrínseco al funcionamiento del sistema, que da cuenta de su propia racionalidad interna. El crecimiento de la población, ligado a las desiguales oportunidades de vida que brindan las distintas regiones, provoca un movimiento migratorio intenso, sea estacional, sea permanente. Al respecto nos referiremos de manera breve al crecimiento demográfico desde una perspectiva estructural y luego, un poco más extensamente, a las características del movimiento migratorio, que como ya hemos señalado, constituye un fenómeno de privilegio para un estudio de la población dentro del tratamiento propuesto.

29 No siempre el desempleo agrícola ha sido pensado como un mal que obstaculiza los intentos de desarrollo económico. A propósito, Marshall Wolfe sostiene en su conferencia sobre cambio demográfico y desarrollo rural en América Latina: 1) que habría que descartar la política de mantener a la población rural en economía de subsistencia hasta que se desarrolle la economía urbana ya que los bajos niveles de vida en el agro lo hacen imposible; 2) descartar la solución que plantea una combinación entre migración rural-urbana y colonización de tierras; 3) que la verdadera solución está en la elevación de la capacidad de absorsión de mano de obra en la agricultura comercial y la disponibilidad de fuentes de ingreso no agrícola en el campo y en los pequeños pueblos. Al respecto se puede consultar Actas 2, Conferencia Regional Latinoamericana de Población, México, El Colegio de México, 1970. 


\section{El crecimiento demográfico}

Dentro de los marcos de una investigación en curso en el Programa Centroamericano de Ciencias Sociales acerca de "Población, desarrollo rural y migraciones internas en centroamérica", Blas Real ha determinado para Nicaragua las etapas que periodizan el crecimiento demográfico. Distingue cuatro momentos que se pueden aislar: a) el período colonial; b) desde fines del siglo xviII hasta los primeros decenios de vida independiente; c) los años de la incorporación de la economía al mercado mundial del café; $d$ ) desde la segunda guerra mundial hasta el presente.

Advierte este autor que no se puede considerar como algo mecánico la relación entre dinámica de la población y cambios importantes habidos en la estructura productiva agraria nicaragüense; sin embargo, dan cuenta de algunas tendencias que la investigación social no puede pasar por alto. Recogemos aquí la propia síntesis que propone:

"Durante la colonia se puede afirmar que la dinámica de población, por un lado expresada en el decrecimiento demográfico (de la población indígena), y por otro, en los desplazamientos forzosos de la población indígena desde las tierras altas a las bajas y los cambios en la forma de asentamiento - concentración por dispersión - son consecuencia del modo en que se insertaron las nuevas formas de producción, esto es, aprovochando, en el caso del añil, las formas de producción de subsistencia existentes; esto significa que la reproducción de la fuerza de trabajo se llevó a un nivel mínimo en el sentido de que una vez que los indios no podían más y morían, se traían más de las tierras altas. Esto último es un cambio radical en las formas de vida de los indígenas lo que acentuó, aún más, el proceso de decadencia de la población."

El segundo período que establece este autor se caracteriza por una recuperación en la fecundidad que se manifiesta a finales de la colonia, persistiendo durante los primeros años de la independencia. En esta eta$\mathrm{pa}$, "aunque las estructuras económicas y sociales quedaron intactas, un cambio importante en las relaciones de producción determinó un débil crecimiento de la población y además una probable estabilización en los desplazamientos espaciales. Esto es válido sobre todo para los años posteriores a la independencia, ya que con la 'abolición' de la esclavitud y el inicio de la inserción de la economía nicaragüense en el mercado mundial, se dan condiciones para una reproducción más amplia de la población (obrera y campesina) para asegurar el proceso de acumulación en vistas de la exportación."

En el tercer período considerado, "la participación definitiva en el mercado mundial a través del café, determina, por una parte, que la población comience a volver a su estado 'natural', desde tierras cálidas (bajas) a tierras frías (altas), y por otra, el tipo de cultivo determina la necesidad de asegurar mano de obra para el tiempo de la cosecha, asegurando la subsistencia de la misma 'cediendo' tierras cerca de las plan- 
taciones, lo que permite, relativamente, un nivel de acumulación más alto al mismo tiempo que la población tiene oportunidades de reproducir su fuerza de trabajo en términos más amplios, lo que da como resultado un crecimiento más acelerado de la población."

La última etapa, menos considerada por el autor por tratarse de un planteamiento más bien histórico, revela el crecimiento explosivo de la población que tiene lugar en la segunda postguerra y que coincide con la generalización del capitalismo industrial a través de la internacionalización de la economía, que junto con la expansión de las técnicas que dan como resultado la disminución de la mortalidad, agravan la tendencia crónica al desempleo manifestada en el fenómeno de la marginalidad.

Una perspectiva de estudio como ésta podría ahondar sobre las causales estructurales del desarrollo demográfico revelando los factores que, mediatizados por un sinnúmero de otros factores que habría que señalar, determinan a largo plazo el comportamiento de la fecundidad. Al respecto, desde ya se podría postular una correspondencia entre determinados contingentes de población y determinadas formas de organización social de la producción que imponen ciertos cultivos. Por ejemplo, un fenómeno digno de estudio es el papel "demográfico" del café en algunos países de Centroamérica. Por el hecho de requerir de una considerable mano de obra en la época de las cosechas, hasta el momento difícil de reemplazar, y por el hecho de localizarse en zonas altas, las más pobladas, el café se ha convertido en un producto que retiene mano de obra, generándose en torno a él una economía que combina la actividad rural con la actividad urbana. Esto se puede comprobar al menos en Nicaragua y en Costa Rica. El contraste es grande cuando se compara el comportamiento de la población en regiones cafetaleras con el que se manifiesta en regiones algodoneras. En este último caso la producción tiende a una progresiva marginalización de la población debido a las posibilidades de innovaciones tecnológicas que este cultivo permite. Una situación diferente se debería apreciar en zonas donde imperan cultivos como las hortalizas que también requieren de mano de obra no fácil de reemplazar.

En síntesis, el monocultivo, incluso el café, no podría ofrecer una base productiva capaz de soportar tasas muy altas de crecimiento demográfico. En primer lugar porque el crecimiento de la producción de alimentos para consumo interno es un perpetuo tropiezo en una economía agraria destinada a la producción para el mercado externo. Esto ya se ha comprobado lo suficiente en América Latina. En segundo lugar, porque la absorción de la creciente fuerza de trabajo lanzada al mercado por el acelerado incremento demográfico, requiere de una diversificación de la economía, en la que, para hablar sólo de los aspectos agrarios, se combinen cultivos de alta productividad pero poco incorporadores de mano de obra como podrían ser el algodón, la palma africana o la ganadería, 
con cultivos en que los aumentos de productividad por hectárea sean logrados por la intensificación de los mismos aunque disminuya la productividad del trabajo respecto de otros productos. Además, la diversificación del empleo agrícola debería ir aparejada con una ampliación del empleo no agrícola, en zonas rurales, que diera ocupación productiva a la población y evitara la congestión en las ciudades que agrava la situación de desempleo al concentrar espacialmente a los desocupados del agro. Por último, el ascenso en el nivel de vida que se podría procurar de esta manera en el campo redundaría en el mejoramiento de las condiciones propicias para la creación de un mercado interno que sentaría las bases de una industrialización autónoma.

$\mathrm{Si}$ esto no es posible en el agro centroamericano, si la producción de una creciente sobrepoblación relativa no es contenida con oportunidad, si sólo se piensa como gran receta en el control de la natalidad, que a lo más puede mantener estacionaria a una población desempleada, los obstáculos se deberían localizar en la racionalidad económica de un sistema de producción basado en la monopolización de la tierra y en la apropiación privada de los recursos, que implanta patrones de producción de elevada rentabilidad para los sectores propietarios y no para la economía en su conjunto. Con esto se podría poner en su lugar la discusión abstracta acerca de la correspondencia entre el ritmo de producción de alimentos y el ritmo de crecimiento demográfico; discusión que a menudo conduce a planteamientos catastrofistas o a callejones sin salida, conjuntamente con estimar en su justo valor las proposiciones acerca del balance entre la disponibilidad de recursos naturales y el aumento poblacional.

\section{La importancia de la migración rural}

Los dos grandes factores que hemos considerado como esenciales para el estudio de las migraciones rurales, y que hemos abordado antes: el problema de la aparición de una sobrepoblación, y la verificación de desequilibrios regionales como efecto de un desarrollo económico desigual, deberían orientar en la formulación de las hipótesis que se desprenden de nuestro modelo.

En primer lugar, se puede afirmar que una de las consecuencias innegables de la desocupación agraria, debería ser la alta movilidad geográfica del campesinado, la cual adquiere carácter forzoso. Esta movilidad, como dice Ernest Feder, es el signo exterior de un profundo mal en toda América Latina rural, y no, como se podría creer desde una óptica liberal, evidencia de una población campesina dinámica que trata de mejorar su propia situación económica y social. No se trata de una respuesta a los estímulos de la competencia dentro del mercado de trabajo; es más bien efecto de la rigidez y exigüidad del mercado de trabajo. 
"En general, los campesinos no andan buscando mejores trabajos que los que tienen, simplemente andan buscando trabajo." ${ }^{30}$ Esta hipótesis es perfectamente verificable por el estudio de los lugares de origen de los grandes flujos migratorios. Sólo a título de ejemplo, pues la verificación de las hipótesis no es el objeto de estas páginas, se pueden recordar dos regiones típicas de expulsión: una, dominada por el latifundio ganadero, como es la Provincia de Guanacaste a que ya nos hemos referido, que muestra una tasa de migración neta de $9.3 \%$ según el Censo de Población de 1963 en Costa Rica; la otra está constituida por los Departamentos occidentales de Honduras, Ocotepeque, Intibucá, La Paz y Lempira, en donde priva el minifundio con sus secuelas conocidas, y que muestran en el Censo de Población de 1961 tasas de migración neta de $36.32 \% ; 12.50 \% ; 20.41 \%$ y $12.97 \%$, respectivamente. En ambas regiones, tan diferentes la una de la otra, no se podría suponer la existencia de un trabajo poco remunerado o indeseable para los campesinos; en una es el minifundio agotado y cada vez más reducido, y en otra el ahorro absoluto de mano de obra que implica la extensión de la ganadería, el factor que cierra el acceso al trabajo.

El otro problema, el de los desequilibrios sectoriales y espaciales, lleva a considerar, en primer término, la polarización entre el campo y la ciudad, y en consecuencia, la estimación relativa de la migración ruralurbana respecto de la migración rural-rural. Ya hemos insinuado la hipótesis de que la penetración capitalista en Centroamérica no ha polarizado los desequilibrios regionales en una contradicción campo-ciudad, por lo menos en el grado en que este fenómeno ha acontecido en otros países de la propia América Latina. La importancia cuantitativa de las migraciones campo-ciudad, que podría llegar a ser muy alta en la región, como acontece con la ciudad de Managua, no va a ser decisiva en el análisis destinado a comprender la causa y la propia naturaleza del movimiento migratorio. Ya nos referiremos a esta cuestión. Pero si no es relevante para comprender la lógica seguida por el movimiento migratorio, lo es desde el punto de vista de los efectos, de las consecuencias económicas y sociales de los flujos migratorios en general. Pero antes de discutir acerca de las cualidades heurísticas de distintos flujos, revisemos la importancia cuantitativa de ellos. Según el Censo de Población de 1964 de Guatemala, los migrantes intrarurales alcanzan el 59\% del total de migrantes del país. En Costa Rica, de acuerdo al censo de 1963 la cifra asciende a $58 \%$. El porciento debería ser más alto en Honduras, pero ostensiblemente inferior en Nicaragua, en donde la migración hacia Managua alcanza un nivel de $41 \%$ del total del movimiento migratorio del país. La dimensión que cobra la migración rural-rural en nuestra región, advierte que el fenómeno se presenta en formas diferentes respecto de otros países de América Latina. La información que se presenta en el cuadro 2 permite una somera comparación entre algunos países escogidos.

30 Ernest Feder, op. cit., pp. 37-38. 
Cuadro 2

Tasas aNuales de Migración a la zona uRbana de varios países de América latina en períodos recientes

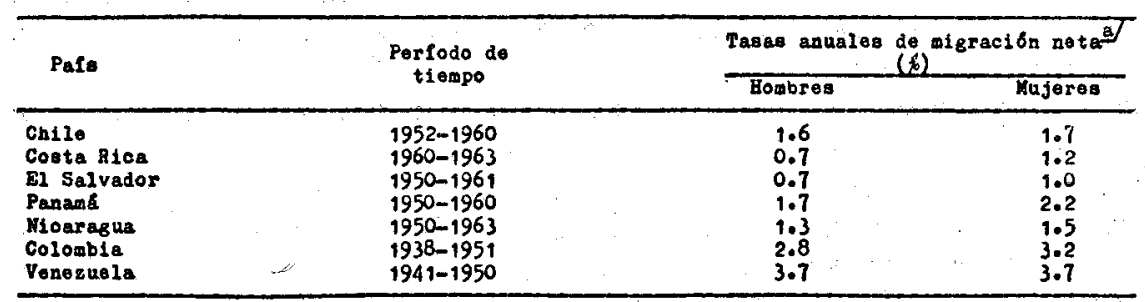

Fuente: Juan Carlos Elizaga, Migraciones a las áreas metropolitanas de América Latina, Santiago de Chile, CELADE, 1970.

a De personas de 10 y más años de edad al final del período.

Según este cuadro, los tres países de nuestra región dentro de los siete seleccionados, son los que muestran un volumen de migración hacia los centros metropolitanos de más bajo nivel. Si se supone una intensidad semejante en el proceso migratorio global, se podría deducir que son los países en donde la migración rural-rural adquiere mayores dimensiones. Esto confirma la tendencia que hemos adelantado respecto de la migración hacia San José y hacia Managua. Pero las cifras insinúan también otro aspecto interesante. Al parecer, el nivel de urbanización no tiene incidencia en la intensificación de la corriente migratoria hacia los centros metropolitanos. Tenemos que Chile, con una población urbana de $54.7 \%$, de las más altas de América Latina, registra una corriente hacia las zonas urbanas relativamente baja. Costa Rica y El Salvador, que tienen la misma tasa anual, registran un proporción mediana de población urbana $(24 \%)$ el primero y una muy baja el segundo $(17.7 \%)$. La información que el cuadro proporciona apunta a la intensidad del proceso de urbanización actual más que al nivel de urbanización existente, y esto no depende necesariamente de factores urbanos, sino que probablemente da cuenta de los procesos que ocurren en el agro. Mientras más fuerte es la sobrepoblación en el agro, más intensa tiene que ser la corriente de población hacia las ciudades.

Esto conduce a pensar que el estudio de las migraciones dentro del agro deben dar mejor cuenta del movimiento migratorio en su conjunto. Al respecto, postulamos que éste se desenvuelve de manera principal, primero en términos temporales, dentro del ámbito agrario, saliendo de él por saturación interna. El propio estudio de las migraciones rural-rural da a conocer las condiciones en que se produce la saturación del agro, ya que mientras constatemos allí regiones de atracción conocemos las válvulas de escape a la presión de la fuerza de trabajo ociosa, pudiendo predecir la situación de total saturación. La importancia de la migración rural-rural en el agro centroamericano revela que aún está lejos el punto de saturación plena. 
El escaso dinamismo de la economía urbana, que no ha alcanzado un ritmo de expansión que se manifieste en una expansión del empleo, conduce a pensar que la migración del campo a la ciudad no se debe a factores de atracción de la economía urbana, sino a factores de expulsión de la economía agraria. Resulta patente, al observar la composición de la población económicamente activa en su evolución en el tiempo (véase la primera parte) que la industria no opera en términos de atracción de mano de obra. Sin embargo, se es consciente de que esto no autoriza a afirmar la pasividad de la economía urbana. En Centroamérica se vuelve imperioso distinguir entre la industrialización y la urbanización. Esta última se desenvuelve con su propia legalidad y autonomía. En realidad, la evolución de la propia economía agrario-exportadora suscita una gran variedad de actividades económicas que se localizan en las ciudades, tales como comercio, transportes, construcción, servicios eléctricos, bancos, etc. La generación de cualquil actividad económica de un cierto volumen acarrea una serie de servicios complementarios, tales como el servicio doméstico, policía, diversiones, etc., con lo cual se establece una corriente de demanda de mano de obra, tanto calificada como no calificada. Pero sin desconocer estos antecedentes, que sin duda actúan en las migraciones, podemos postular que en la migración campo-ciudad, estos factores de atracción se activan una vez que se ha producido una cierta saturación de empleo agrícola. En términos sociales, esto es, generales, si existen oportunidades de empleo en el agro, el campesino tiende a permanecer allí, en su mundo más familiar, en un trabajo para el cual se siente más capacitado, por lo cual creemos que las migraciones tienden a constituirse primero en desplazamientos dentro del agro, salvo cuando habitan regiones vecinas a los centros urbanos. Agotada la alternativa de la migración rural-rural, adquiere mayores dimensiones la migración campo-ciudad.

Al formular estas hipótesis nos basamos en la relación de causalidad que se da entre factores de atracción y factores de expulsión, respecto de la dirección que adopta el movimiento. Si no se observa un dinamismo económico que se traduzca en la ampliación del empleo, no se podría sostener que la ciudad sea un centro de atracción de población. Lo que se observa en la ciudad es una extraordinaria ampliación de los servicios, a veces totalmente marginales en términos del sistema económico, que generan un ingreso mínimo, acompañado de subempleo y hasta de desempleo. Por lo tanto, resulta más lógico pensar que las personas venidas del campo no han llegado atraídas por una mejor alternativa de empleo, sino porque han dejado de tenerlo en el campo. En esto coincidimos de nuevo con Ernest Feder, quien afirma, a partir del análisis de los siete países incluidos en el estudio de CIDA: "De hecho, dado el alto nivel de desempleo urbano, no podemos señalar, en las condiciones actuales, los desplazamientos de la fuerza de trabajo de las ocupaciones primarias a los sectores de servicio o industriales como un signo de progreso 
o de desarrollo económico. Es cierto que, durante los últimos decenios, millones de campesinos han emigrado a las ciudades y pueblos y ha disminuido la proporción de población rural. Esto ha ocurrido en países con un incipiente desarrollo industrial, como en aquellos que no han tenido prácticamente ninguno. Pero gran parte de la población rural que vive en los barrios miserables de las ciudades está desocupada o subocupada. En el contexto latinoamericano, el progreso sólo puede ocurrir una vez que haya aumentado radicalmente la ocupación en la agricultura. Hasta ahora, la migración del campo a las ciudades no ha eliminado la desocupación rural. Es razonable suponer que, a pesar de la continua migración de las familias rurales a las zonas urbanas, la desocupación en la agricultura está aumentando en vez de disminuir, y que los factores que en el pasado han contribuido a producirla, también contribuyen a intensificarla en el transcurso del tiempo" ${ }^{31}$

Apoyados en estos antecedentes y en estas consideraciones llamamos la atención acerca de la importancia de la migración rural-rural, que puede dar la clave para la comprensión de la migración rural-urbana. En efecto, ésta se puede entender como el escape que opera por saturación del movimiento rotatorio que hemos postulado entre los dos polos de la economía rural, el polo propiamente capitalista y el polo de usufructo que se han definido más arriba.

\section{La doble orientación del movimiento}

Los datos anteriores acerca de la incorporación de mano de obra al sector industrial, han llevado a descartar la industrialización como una causal de relevancia en el movimiento migratorio. La asociación entre industrialización y migración, válida para algunas regiones aun de América Latina, no es determinante en Centroamérica en el estudio de esta última. Aquí, los desequilibrios espaciales que introduce la modernización capitalista deberían ser abordados desde otra perspectiva. De igual modo, la asociación clásica entre desarrollo capitalista y concentración espacial de la población debería ser relativizada. Sin embargo, en los mejores estudios teóricos acerca de la naturaleza de las migraciones internas realizados en América Latina con un enfoque estructural, se tiende a concebir la migración como un flujo que va desde regiones relativamente subdesarrolladas hacia regiones relativamente desarrolladas, adquiriendo los llamados "factores de cambio", un carácter dinámico que incluye, por una parte, una constatación del desarrollo capitalista, y por otra, un fenómeno de concentración espacial, aunque a veces los factores de cambio impliquen de manera circunstancial, expulsión de población. Esto resulta plenamente válido en estudios de largo plazo en los que se explican las grandes tendencias de los desplazamientos espaciales de la

31 Ibid., p. 35. 
población. Pero si hacemos un corte en el tiempo, correspondiente al período de vigencia de un sistema económico-social como el que hemos caracterizado, las tendencias de los flujos migratorios pueden resultar diferentes.

El desarrollo capitalista tiende a ser concebido en cierto modo como lineal, aunque contemple etapas de involución parcial. Al mismo tiempo, el movimiento de la población se presenta en forma también lineal, en términos de reducción de la fuerza de trabajo empleada en relaciones de trabajo no propias de una economía capitalista, y aumento del empleo capitalista. En última instancia, el propio desarrollo capitalista es percibido de manera implícita como expansivo, tendiente a incorporar fuerzas productivas que proceden de la disolución de anteriores relaciones de producción. Hemos visto que el postulado acerca del carácter no expansivo del capitalismo agrario centroamericano es plenamente defendible, con lo cual el flujo de los movimientos migratorios en la región no tiene por qué presentar un carácter lineal y progresivo. La población, aquí, no se mueve solamente de regiones de relativo subdesarrollo hacia regiones relativamente desarrolladas, sino que por el carácter "híbrido" del capitalismo agrario centroamericano, que mantiene, porque las necesita, las áreas de economía no capitalistas, los movimientos de población pueden darse tanto desde subdesarrollo a desarrollo como a la inversa. Esto lo veremos mejor a propósito de la dirección de los flujos.

Desde este ángulo resulta de suma utilidad la consideración atenta de los factores de atracción y los factores de expulsión, que en su interacción establecen la dirección que adopta el flujo migratorio. Esta distinción se muestra válida dentro de un marco de explicación estructural del movimiento migratorio y enriquece plausiblemente el análisis. Al respecto podríamos postular lo siguiente:

a) Para el análisis de la migración rural-urbana, que incluye en la región una migración hacia los centros metropolitanos que oscila entre 25 y $30 \%$ del total de los migrantes, salvo hacia Managua que registra $41 \%$, los factores de atracción se deberían considerar como teóricamente irrelevantes, ya que el crecimiento industrial y el dinamismo general de la economía urbana no atrae mano de obra. Con el aumento del sector servicios, lo lógico sería pensar que la incorporación de los migrantes se da principalmente en ese sector, por lo general de escasa productividad, y en realidad el sector menos dinámico de la economía. Este sector, en toda América Latina, no es en sí de "atracción" sino resumidero del sobrante de población, la cual por cierto no va a proceder de la industria sino del agro. Lo decisivo entonces para explicar la migración rural-urbana, debería radicar en los factores de expulsión, que habría que situarlos con toda seguridad en la economía rural. Ya nos referimos a los otros factores de atracción que toman parte en el flujo hacia las ciudades, tales como los servicios gubernamentales, el comercio, la construcción, etcétera. Tales elementos parece que actúan desde el momento en que 
operan ya los factores de expulsión situados en el agro, los cuales serán los decisivos para el análisis;

b) Para el análisis de la migración rural-rural, el quid de la explicación estructural tendrá que estar en la composición y articulación entre los factores de atracción y los de expulsión. En algunos momentos y para algunas regiones, un tipo de factores se manifestará como predominante y subordinará al otro, pudiendo en coyunturas diferentes alterarse la relación. En la relación entre los factores de expulsión y los de atracción deberá existir un centro generador de la energía migratoria, un nudo vital de movimiento de sístole y diástole, que no podría ser otro que el núcleo capitalista agrario, cuyo comportamiento de contracción o de expansión deberá estar asociado al flujo y reflujo de la población migrante.

En la determinación de los factores de expulsión y los factores de atracción de un flujo migratorio', interviene el análisis de la estructura social que debe dar cuenta de la forma concreta de organización de la actividad productiva en diversas unidades geográficas. Estas unidades tendrían que ser observadas luego en términos de su comportamiento como localidades de crecimiento o de decrecimiento demográfico relativo. Aquí, el papel preponderante lo tiene la estructura económico-social, de tal manera que aun si la determinación censal del carácter positivo o negativo de la localidad en cuanto a la migración neta, no corresponde a la naturaleza socio-económica de la región, es muy probable que lo que esté aconteciendo sea la presencia de un flujo migratorio más amplio, que por efectos de las dificultades metodológicas de medición censal de las corrientes, no alcanza a ser captado por el investigador. ${ }^{32}$

\section{La dirección de los flujos migratorios}

De acuerdo a las consideraciones anteriores pertinentes al capitalismo agrario y de la incidencia que éste demuestra en los movimientos de población, podemos postular una doble orientación de los flujos migratorios; probablemente simultáneas en el tiempo: a) Un primer movimiento que procede de zonas de economía de subsistencia, constitutivas del contorno de usufructo del sistema capitalista. Esto se da en esencia cuando, por efectos de la coyuntura económica, cuyos determinantes intentaremos definir más adelante, algunos productos, por ejemplo un producto básico de exportación, experimenta cierto auge. Pensemos en lo que significó en algunos momentos el café en la región, luego el banano y el algodón; $b$ ) Un segundo movimiento, que al presentarse en diferentes zo-

32 Al respecto se torna de gran utilidad la distinción propuesta por Blas Real entre un flujo migratorio, que se define por la polarización estructural de un centro de rechazo y un centro de atracción, y una corriente migratoria, que se refiere al movimiento medido censalmente. Puede que ambos no coincidan, pero debe entenderse entonces la corriente como la parte de un flujo no conocido de manera plena. 
nas geográficas puede coincidir temporalmente con el anterior, procede de una región de economía capitalista agraria, y se dirige hacia una zona de economía de subsistencia. Es el movimiento de reflujo que tiene el núcleo capitalista de la economía. Debería acontecer, de manera principal, por obra de una innovación tecnológica importada, que se incorpora expulsando mano de obra. La población expulsada del núcleo capitalista se refugia en el contorno de usufructo. Este movimiento también puede ocurrir cuando un producto agropecuario que requiere poca mano de obra iomienza a cobrar importancia creciente, como acontece con la ganadería de carne o cuando un producto más absorbente de mano de obra decae por efectos de la coyuntura económica, como se puede comprobar con el banano que empieza a ser reemplazado por la palma africana.

Resulta pertinente advertir, a fin de obviar dificultades posteriores, que la distinción entre un sector capitalista de la economía y un contorno de usufructo, no corresponde exactamente a una zona de latifundio enfrentada a una zona de minifundio. Hemos afirmado que el latifundio más desarrollado en términos capitalistas puede comprender, y comprende la mayoría de las veces, internamente o en su periferia, una zona de usufructo. De tal manera que una migración que vaya de latifundio a latifundio puede ser en términos cualitativos, tanto un movimiento del núcleo capitalista hacia el contorno de usufructo, como el movimiento inverso, como incluso un movimiento de núcleo capitalista a otro núcleo capitalista, o de economía de usufructo a economía de usufructo. Un ejemplo podría aclarar esto. Si observamos en Costa Rica un desplazamiento que va de la Provincia de Guanacaste a la Provincia de Limón, dos provincias en los extremos del territorio nacional, el movimiento puede ser desde el punto de vista cualitativo de una economía de usufructo (colonos guanacastecos) hacia una economía capitalista (latifundio bananero). El movimiento puede ser perfectamente de latifundio a latifundio, desde la perspectiva del tipo de propiedad según tamaño. Pero bien puede darse el movimiento inverso, es decir, al permanecer de latifundio a latifundio, puede venir de un núcleo capitalista (un trabaiador ganadero desplazado por la mecanización agrícola) hacia una zona de usufructo (la periferia de una plantación bananera). En nuestro ejemplo consideramos un movimiento que va de latifundio a latifundio, pudiendo darse entre minifundio y minifundio, permaneciendo presumiblemente dentro de una economía de usufructo, o bien de un latifundio a un minifundio, o bien de un minifundio a un latifundio. La categoría del tamaño es sin duda una categoría importante, pero no es el eje central de nuestro modelo. Lo que más nos interesa captar son las oscilaciones de la producción capitalista, que estimamos de vital importancia para los vaivenes de la mano de obra campesina.

La primera conclusión que podríamos sacar acerca de las migraciones internas en Centroamérica, reside en que, a causa del carácter "híbrido" del capitalismo agrario, que combina el núcleo capitalista con el 
contorno de usufructo, éstas no poseen una dirección lineal que va desde una zona de menor desarrollo hacia una zona de mayor desarrollo, sino que el tránsito se da indistintamente de ida y vuelta entre ambos términos. Por lo tanto, no resulta aplicable a nuestra región una asociación positiva entre desarrollo capitalista y concentración espacial de la población. Por las razones ya señaladas, y por la dialéctica alternativa de absorción y repulsión de mano de obra, el propio capitalismo agrario manifiesta una lógica de desarrollo no lineal y progresiva, de disolución de formas no capitalistas de producción, sino una lógica zigzagueante y de desarrollo en espiral. Las características del desarrollo de la región deberían manifestarse en el plano de los desplazamientos de la fuerza de trabajo. Por esto, podemos postular para las migraciones internas una lógica de movimiento similar, es decir, carente de continuidad ascendente. El movimiento migratorio debe transcurrir dentro de una órbita circular en el ámbito agrario, que comprende incluso su propia fuerza centrífuga de expulsión del círculo de rotación en el agro, en dirección hacia las ciudades, las cuales operan como el receptáculo final de movimiento. Así se explica desde el estudio de las migraciones intrarrurales, la propia migración hacia la ciudad, entendida como la válvula de escape que funciona cuando el movimiento rotatorio intrarrural se ve saturado. Un caso típico lo constituye la alta migración hacia la ciudad de Managua, que se eleva al $41 \%$ del total de las migraciones internas del país. Allí no se dan factores estructurales de atracción dignos de considerarse con anterioridad a 1972. Sólo parece ser que el sector servicios se acrecienta con la migración. A partir de esa fecha, y como consecuencia del terremoto, las tareas de construcción adquieren un dinamismo extraordinario, cambiando la configuración del fenómeno. La migración hacia la ciudad no puede provenir sino de la desocupación rural. La "anormalidad" de este fenómeno prematuro de concentración poblacional en una zona estructuralmente no de atracción, esto es, carente de dinamismo expansivo, queda manifiesto cuando se observa que bien podría darse aquí una migración inversa, urbano-rural, como efectivamente ha ocurrido cuando, con el fin de descongestionar la metrópoli, el gobierno organiza el traslado de población desde Managua hacia la frontera agrícola. En regímenes de economía preponderantemente agraria no deberían extrañar estos fenómenos, tan poco habituales, de migración urbano-rural.

Si abordamos ahora el problema de cuáles pueden ser los factores que inciden en la determinación del sentido del movimiento migratorio, tal como se ha considerado, tendríamos que concluir que el doble movimiento, desde y hacia los núcleos de capitalismo agrario, se establece de acuerdo a la coyuntura económico-política, particular y cambiante, pero dentro de un marco de relativa estabilidad. Esta coyuntura podría variar por efecto, al menos, de los siguientes factores: $a$ ) Las fluctuaciones del mercado externo, que provocan en la agricultura una intensificación o una declinación de algunos cultivos. Con esto, unas zonas pueden adquirir preponderancia temporal respecto de otras. La orientación prioritaria de la 
agricultura al mercado externo es una de las causales más directas de los desequilibrios regionales de la economía centroamericana. Los movimientos de población, en consecuencia, deberán seguir la dirección señalada por el curso de estas fluctuaciones; b) Las transformaciones tecnológicas, que operan sobre todo en las regiones de economía capitalista como un factor decisivo de expulsión de mano de obra obligada a refugiarse en el contorno de usufructo. Los casos más evidentes de migraciones motivadas por este factor tecnológico lo constituyen los despidos masivos en las empresas bananeras; c) Los intereses competitivos de sectores diferenciales dentro de los grupos dominantes. En ocasiones pueden determinar la intensificación de algunos cultivos en desmedro de otros, dinamizando algunas regiones y relegando otras. Un caso representativo de este fenómeno podría ser, quizás, la intensificación de la ganadería de carne en Costa Rica, que se desarrolla bajo el amparo del aparato estatal, que fortalece esta actitvidad en desmedro de otras, que crea una vasta zona especializada y se convierte en una zona de expulsión por excelencia; d) El uso capitalista de la tierra, que le otorga una gran movilidad como recurso económico (compraventa, arrendamiento, especulación, etc.). Este es otro factor que puede determinar la dirección de los flujos. En algunas regiones deben generarse procesos de transferencia de tierras que cobran un nivel significativo, procesos de concentración de la propiedad o de parcelación de la misma. Este es otro factor de desequilibrio, en la medida en que la "movilidad" de la tierra, por factores variables en cada caso, promueva tanto el desenvolvimiento como el estancamiento de una región. Esto debe desembocar en cambios repentinos en el uso de los recursos, y en transformaciones del nivel del absorción de la fuerza de trabajo.

La combinación de estos factores, al menos, hará que en determinadas contingencias el núcleo capitalista de la economía, focalizado en algunos productos en auge, se comporte como polo positivo del desplazamiento, como factor de atracción de la población. En otras coyunturas, el juego de los elementos mencionados hará que el núcleo capitalista de la economía agraria se comporte como factor de expulsión de mano de obra, surgiendo el contorno de usufructo como el polo positivo del desplazamiento. Dentro de la dialéctica postulada entre el núcleo capitalista y el contorno de usufructo, términos que adquieren validez sólo como categorías analíticas y no como determinantes espaciales o regionales, el polo decisivo, ya lo hemos afirmado, estará constituido por el núcleo capitalista, que es el principal afectado por los ciclos de expansión o de contracción. El contorno de usufructo se deberá comportar como una reacción proporcionada a la evolución del núcleo capitalista. En este sentido se le puede considerar como un polo pasivo frente al otro que es el activo. Sin embargo, desde el punto de vista del desplazamiento espacial, puede ser tanto un polo positivo, de atracción, como un polo negativo, de expulsión. Pero su mismo carácter de positivo o negativo, estará determinado por la dinámica del polo capitalista. 